\title{
Does German Cultural Studies need the Nation-State Model?
}

\author{
With contributions by Yael Almog, Kirsten Belgum, Benjamin Biebuyck, \\ Stephen Brockmann, Vance Byrd, Necia Chronister, Nicole Coleman and \\ Lisabeth Hock, Carol Anne Costabile-Heming, Gisela Holfter, \\ Jennifer Ruth Hosek, Kathrin Maurer and Moritz Schramm, \\ Patrizia C. McBride, Jan Mieszkowski, John K. Noyes, Benjamin Robinson, \\ Carrie Smith, Scott Spector, Brangwen Stone and Katie Sutton, \\ Heather Sullivan, Per Urlaub, and Kirk Wetters.
}

The nation-state model has long been the basis for the institutional structure in place to teach languages, literatures, and culture at American universities and elsewhere. Nationalism was in fact formative for the establishment of the discipline of German literary and cultural studies itself - and not something brought into its disciplinary history from the outside, as Jakob Norberg, building on earlier research (see for instance Costabile-Heming/Halverson; Hohendahl, German Studies; Denham/Kacandes/Petropoulos, and McCarthy/Schneider), in a recent issue of the German Quarterly has shown ("German Literary Studies and the $\mathrm{Na}$ tion." GQ 91.1, 2018, pp. 1-17). Over the past few decades, this history linking our profession to the nation-state model has often been questioned by those teaching German literature and culture, while the status of German in general was institutionally quite secure and there was little reason to think about structural changes. This, however, has changed. Not only do fewer students in the United States and across the globe opt to major in German; administrators at many institutions increasingly prefer language, literature, and culture departments to be part of larger structures, thus (implicitly or explicitly) also questioning the value of the nation-state model that so long has been part of our disciplinary history. In addition, scholars themselves in their teaching and research increasingly choose to emphasize the many global contexts of German literature and culture as meaningful for the study of German itself.

With this history and the current pressures that our field faces in mind, the German Quarterly asked a number of scholar-educators with a wide variety of academic backgrounds to reflect on these developments with an eye on our discipline's institutional history and future. We asked them to engage with our discipline's history, to point to dangers and opportunities, and (where possible) to suggest creative and pragmatic responses to the conflicting demands that we are facing today as a discipline. In their responses, we encouraged our authors to reflect on the following three questions.

- How important / decisive has the nation-state model been within the history of your specific research area(s) or field of expertise? 
- How important is the nation-state model for your current research and teaching? Do you see this link as positive or negative? Have you (intentionally or not) moved away from a strictly nation-based model in both areas?

- Can you imagine an institutional structure in which the study of German language, literature, and culture can thrive, but that also productively incorporates our discipline's global connections and links with other units?

Below are our authors' responses. As was to be expected, the answers to the questions asked take the future of our discipline in many different directions-indicative, perhaps, of a pragmatism and diversity that are both real strengths of our field of study. Without a doubt, the contributions collected here offer an incomplete overview and also point to the need for further discussion at this specific moment in our discipline's development. Rather than formulating "definitive" answers, this forum is therefore intended and will hopefully serve as the starting point for further debate.

As always, $G Q$ is interested in its readers' responses. Do not hesitate to contact us with your comments and check our facebook page (https://www.facebook.com/ TheGermanQuarterly/) for updates.

Carl Niekerk

niekerk@illinois.edu 


\section{Responses}

\section{German-Jewish Studies beyond the Nation-State}

Since its debut, the study of German culture has shaped German national character. Such figures as the brothers Grimm and Schlegel impregnated in the study of German literature their respective visions of the German people and disseminated collective myths that have become constitutive of German nationhood. Examining this history, Jacob Norberg has recently appealed to the transformative potential of German Studies as an academic field by asking it "to remake itself into the meta-national discipline par excellence" (14). Yet aside from raising awareness to the history of the field, how can scholars of German Studies uncover nationalist agendas instead of reinforcing them? Norberg mentions German-Jewish studies as a model for approaches critical of nationalism, for perspectives that unearth the cultural homogeneity at the core of nationalism (13).

Norberg is not the first one to turn to Jewish studies as the litmus test of the national impetus behind the study of German culture. Scholars have pondered the centrality of Jewish authors to the canon of modern German literature before as indicative of postwar transformations of German nationhood (Anderson; Morris). The surge of German-Jewish studies in the United States since the 1980s paralleled the steady support of this subfield in Germany, where German-Jewish studies built on transatlantic cooperation (Isenberg). As I opt to suggest, German-Jewish studies reveal not only the effort to study German culture through a resistance to Germanistik's nationalistic past, but also the complexities behind this attempt. The attention to Jewish authors hardly allows one to leave behind the national history of German Studies given that the wide support of this attention in Germany embodies the aftermaths of German nationalism.

In our times, the appeal to make German Studies a discipline that confronts national apparatus leads to a conundrum. As Norberg notes, today, the attraction to German Studies derives from Germany's status as the current "EU hegemon" (4). This vision behind German nationhood diverges significantly from nationalist trends of the eighteenth and nineteenth centuries. Germany owes its current cultural dominance to its pertinence in facilitating European and international collaboration. In the last decade, Germany has attracted many immigrants, and its relatively accommodating policies toward some groups of refugees became its trademark. These recent policies contrast with separatist trends in the United States and in the United Kingdom. Consequently, German nationalism currently draws its power from its pluralistic vision (although this vision is not translated into concrete open-door policies, and notwithstanding the ethnic, cultural, and religious biases behind European notions of cosmopolitanism). The accentuating of ethnic and linguistic pluralisms in literary studies aligns well with Germany's current model of nationalism rather than transgressing it. 
Mark M. Anderson's essay “German Intellectuals, Jewish Victims: A Politically Correct Solidarity" (2001) traces the treatment of Jews in post-1968 Germany as a continuing influence on German Studies. According to Anderson, the engagement with German-Jewish authors in German literature departments-both in Germany and in the United States-is disproportional to this literature's scope within the German canon. Anderson points out the centrality of such Jewish authors as Benjamin, Celan, and Kafka to German Studies. He thus contends that German intellectuals have overstated and idealized the cultural legacy of Jewish authors. The dominance of Jewish authors in German literary studies is evident in the curriculum in the United States, Anderson argues, even when the social and political conditions diverge drastically between the countries.

Anderson's essay does not spell out the exact ways in which German-Jewish authors were exported to American academia. One is led to assume that the canonization of Jewish literature in Germanistik transformed German Studies on a global scale. Anderson does touch on the success of this export, noting that in the United States German Jews are associated with the history of the Second World War that draws students' attention: "To increase undergraduate enrollments, German professors here are obliged to reduce the canon of German literature to a tiny handful of teachable authors who often have a Jewish background. They are also forced to skew courses away from literature toward the study of persecution, exile, and genocide" (9). Americans' interest in the Holocaust differs greatly from the "political correctness" that provokes the German admiration of Jewish authors in Anderson's mind. Notwithstanding this disparity, Anderson argues, the search after reconciliation, a guiding principle of contemporary German nationhood, impregnates German Studies on a global scale and leads to major biases in selecting a new canon at the expense of some of the constitutive figures of German literature.

In reference to the topic of this special forum, I would like to point out that the version of nationalism that Anderson traces among German intellectuals since 1968 is evidently at odds with the celebration of the German national character in Romanticism. The admiration of Jewish authors of liminal national and linguistic background (like Celan and Kafka) does not transgress the nation-state model; rather, this tendency could be said to make agreeable German nationalism in the present.

Benjamin, Celan and Kafka are still pillars of German Studies in both Germany and North America. Moreover, the cultural tendency that Anderson correlates to German intellectuals still appears prevalent: the broad support of Jewish culture in Germany is steady and the resilience of this trend appears to be steeped in historical guilt. The past decade has only amplified the appeal of German nationhood to visions of religious acceptance and ethnic toleration. It can be argued, therefore, that the admiration of Jewish authors to which Anderson points in his 2001 essay has grown from an inner cultural code, an organizational principle of the German public sphere, into a token of Germany's international stature.

I would like to point out that Anderson's position separates academic cultureswith the intellectuals that ostensibly run them-from the figures they study. This 
position portrays German-Jewish authors as objects, or social capital, to be disseminated in tandem with cultural trends. The view of German-Jews as cultural pawns overlooks, for instance, Hannah Arendt's controversial comments on American racial segregation. It likewise disregards Günther Anders's reflections on the use of atomic weapon or Adorno's inquiries into American radio and television cultures. As these examples show, German-Jewish authors evade their correlation to a singular national culture-and thus, also to deterministic national impetus. Authors are not merely a commodity to be taken on by scholars who aspire to develop a scholarly curriculum compliant (or recalcitrant) to national agendas.

The view of authors as passive pawns does not account for the transnational activity that guides the development of German literature to the same extent that it shapes its scholarship. Our choice of a literary canon, Norberg and Anderson importantly remind us, hones the ideological footprint of our scholarship. GermanJewish Studies straddle a lineage of intellectual inquiries that reflect on the establishment of a literary canon while questioning - reflectively and performatively - the idea of a coherent national character. I would like to point out that this tradition instills in German Studies the consideration of the ethical implications of scholarship: in so doing, this tradition has construed the scholar as an empirical person rather than an objective and calculated outsider to the chronology of nationalism. Such figures as prominent literary scholars Ruth Klüger (in the United States) and Peter Szondi (in Germany) developed a career that echoed their personal stories of forced migration. Other Jewish intellectuals, including Margarete Susman and Hilde Domin, reflected on the cultural valence of literary forms while engaging in poetic writing in German - creation that signaled their exceptional political choice to remain or return to the German-speaking cultural arena. German-Jewish Studies jog our memory that scholarship is transformed constantly by migration, relocation, and reorientation. Forms of mobility thus shape the affiliations between scholars and authors. They are a constant reminder that the ideological footage of their work is not given entirely to scholars' free choice.

Yael Almog

Durbam University

\section{Language Matters}

The question "Does German Cultural Studies need the Nation-State Model?", posed by the German Quarterly, touches on important issues, but it should be slightly rephrased. Since German is an official language of several Central European states, it does not make sense to refer to any one "nation-state" (the geographic region where German is spoken is not as large or diverse as that of Spanish and Arabic, but the issue is similar). Certainly, institutions and funding 
agencies of Germany, Austria, and Switzerland will continue to figure large in our scholarship and teaching in North America. More importantly, we should not conflate language with the nation-state. Doing so is unnecessary and can lead to confusion. Thus, if the question intends to ask: "Does German Cultural Studies need the German language?" my answer would be "yes." But even then there is not just one model that might prove useful to our field. Before I address that issue, however, some clarification is in order.

While Jakob Norberg makes a good point that the academic study of German literature in the German lands arose alongside the push for a German nationstate, his analysis obscures a few important elements. First, German literature has always been replete with voices that were skeptical of an emphasis on national distinctiveness and nationalism. Even as Gotthold Ephraim Lessing advocated for a German national theater he was writing works such as Ernst und Falk. Gespräche für Freimaurer (1778) that argued for knowing when the focus on national specificity ceases to be a good thing. In the wake of the Romantic preoccupation with the Germanic past there were those such as Heinrich Heine who criticized nationalist obsession with biting sarcasm, as did Friedrich Nietzsche, Heinrich Mann, and Kurt Tucholsky, to mention just a few cultural figures. The fact that Heine wrote his Deutschland. Ein Wintermärchen (1844) while in exile in Paris should remind us that German culture does not just occur within the states where the German language predominates.

Second, we should not lose sight of the enormous amount of transnational influence that exists in cultural production. This is not just true for the present moment when migration and digital media have inextricably linked cultures across the world. Even in the nineteenth century, the period in which interest in creating a nation-state in Germany began in earnest, influence across national boundaries (and linguistic divides) was profound. My work on the periodical press, travel writing, encyclopedias, and geographical magazines in that period has shown how much transnational borrowing and even outright copying occurred in publishing. Thus, while German culture's past and present is a powerful example of the operations of national conceptions, it is also a rich terrain for investigating the contestations and limits of the national ideology.

Third, as the essays in Transatlantic German Studies: Testimonies to the Profession (Lützeler and Höyng) demonstrate, research and teaching about German culture from abroad introduce novel points of view to the study of national cultural production. Our work as North American academics, regardless of our respective countries of birth, does not take place in Central Europe, but rather west of the Atlantic. Why does this matter? As scholars, we are, of course, connected to Germanisten in Europe. We attend conferences with them, read their work, and include them as part of the audience for our publications, even if most of what we publish here is in English. But even though Germanistik in Europe has taken a transnational turn (with the study of Kulturtransfer or Migrantenliteratur), our location brings additional transnational perspectives to the subject. This stems in 
part from the cultural questions raised by North American humanities scholars in related fields, but also from our institutional context. Unlike academics in Germany, Austria, or Switzerland, our work involves mediating an understanding of German culture from a distance, a challenge that numerous volumes about the place of German Studies in North America have addressed for decades.

But the subject of German Studies on this continent has changed in recent years. Part of this has involved focusing both on the unique aspects of Germanlanguage literature and culture and on the parallels, connections, and distinctions among cultures, including across national boundaries. Academic programs have begun to emphasize the connections between German and other cultures. Just a few of the many examples are the addition of an "Interdisciplinary German Studies" major at Pittsburg (www.german.pitt.edu/undergraduate/german-major) and the collaboration of Notre Dame and the University of Georgia to "reenvision" German Studies through European integration (Kagel and Donahue). Such supplements to existing German major programs might in part be a response to shrinking enrollments in German programs-i.e., a way to reach a broader audience-, but they also express a recognition that the study of language and culture goes beyond the limits of any particular state.

Thinking beyond the nation-state also opens up institutional opportunities for German Studies faculty. Germany is central to the project of European integration and at the University of Texas at Austin focusing on this has enabled our faculty to teach almost all sections of the required introduction course for the European Studies major. It has been a way to make German culture (albeit in English) more visible to students across campus. At Texas A\&M University it was the German faculty that proposed an institutional consolidation with International Studies as a way to reinvigorate all of the university's language and culture programs (catalog.tamu.edu/undergraduate/liberal-arts/international-studies/). Each institution offers different opportunities and limits. The common task is to be creative and flexible and to think outside the constraints of the nation-state.

Which brings me to the issue of language. Many recent educational innovations in German Cultural Studies education involve teaching students in English. In terms of research most of us who work in North American publish predominantly in English. Colleagues at institutions large and small have been challenging traditional views of the place of language in the German Studies curriculum in other ways as well. Increasingly, they recognize that for North American students engaging with the German language and its culture is not a monolingual, or even an interlingual project (between German and English). Rather it involves a range of multi-lingual contexts related to the multicultural nature of European and North American societies (see the Eaton Group). This has been borne out for me by the fact that in recent decades ever more students in upper-division German classes either are native speakers of languages other than English or are also simultaneously studying other (sometimes non-European) languages. And they bring examples from those languages to bear in our discussions of German literature, culture, and language. 
But even acknowledging such linguistic intersections, the German language (and not one or more nation-states) must remain the crucial tool of our trade. A facility with the language is the avenue that gives us access to German-language culture. If we give up that expertise or if we consider it no longer central to our programs then much of what we teach could be covered in history departments where film and media have entered the undergraduate and graduate curricula, in English departments that teach Kafka, or in theater programs that perform Brecht. But those offerings lack the insights into the language. For students and scholars to engage immediately with a culture, they need direct access to it, to how it operates, and to the ways in which language creates and mediates meaning. Our academic discipline is about the process of cultural transmission that includes an awareness of and attention to the importance of semantics, idiom, register, and culturally specific genres. Students come to German classes to explore and improve their proficiency in German, even when this interest is in support of future work or study in other fields. If the German language does not remain central to our work in terms of both scholarship and teaching, our field will de facto no longer be German Cultural Studies and our programs (regardless of their institutional homes) will disappear.

What is the future of German Cultural Studies in North America? In diverse ways our colleagues are already developing innovative institutional structures that incorporate global connections and linkages with other academic units. What these examples show is that local institutional frameworks and flexibility are more relevant to innovation than a one-size fits all manifesto for the field as a whole. Some models will address the role and place of a "national language." Others may make connections among various nation-states the center of their focus.

For years now, thinking about the place and the future of German Cultural Studies has been the focus of conference panels and collections of essays published in North America. Perhaps that rigorous tradition of self-examination is the unique aspect of our discipline. Two recent volumes Taking Stock of German Studies (Costabile-Heming and Halverson) and Transatlantic German Studies (Lützeler and Höyng) contribute further thoughtful ideas about the various ways in which our field can and must change to remain vibrant and viable. The conversation shows no sign of abating. That is a good thing.

KIRSTEN BELGUM

The University of Texas at Austin

\section{The Nation-State Paradigm in a Country under Ongoing Federalization: Ger- man Studies in Belgium}

The question whether or not there actually exists a common academic, and therefore national, space in Belgium - in the field of German Studies or in any other 
discipline-is not an innocent one. Any answer to it, affirmative or negative, can be seen as, and to some extent is, a political one. From the country's very beginnings as a state in 1830, Belgium consisted of two language communities that were more or less of equal size, yet underwent very incongruous economic and social developments. After World War One, a small German-speaking community in the Eupen/Sankt-Vith area was split off from Germany and incorporated by the Belgian state. Since World War Two, this multilingual context was the setting for a political history of progressive federalization. As a result of this process, the Dutch-speaking (or Flemish) north, the French-speaking south, the bilingual (and nowadays explicitly multilingual) capital, and even the small east-Belgian German community gradually obtained regional autonomy and became increasingly responsible for policy matters concerning culture, economy, and-for the two large language communities - (higher) education and research (there are no academic institutions in the German-speaking part of the country). Consequently, two separate academic realities have come into being that exist and operate more or less independently from one another, even though there still are a limited number of nation-wide organizations, such as the Belgian association for German studies (BGDV, or Belgischer Germanisten- und Deutschlehrerverband), addressing German language issues on the level of federal, regional, and communal governments. Yet, in a country in which even sports leagues have been federalized, such organizations tend to become cultural fossils, reminding us of what a nation-state paradigm must have meant in a country that never really fitted into that very paradigm itself.

The oldest German departments at Belgian universities date back to the last decade of the nineteenth century. All universities, both in the French- and the Dutch-speaking part of the country, had a strong francophone orientation, since French was the common language of the educated elites and of international scholarly exchange. German was introduced in the academic curricula at a time during which the cultural and political influence of Wilhelmine Germany in Western Europe drastically increased. It was part of a philological program aiming at the Germanic languages in general and Dutch, English, and German in particular-the so-called tradition of "Germanic philology" (see Demoor, De Smedt). This program had a strong historical and encyclopedic focus and wavered between a fascination with the richness of German culture and a cautious distance from it, fed by the age-old animosity between the "Germanic" and the "Romance" parts of Europe, the border between which ran (and still runs) straight through Belgium. However, in spite of the nationalistic overtones that may at times occur in the French and Dutch philologies, representing the two main language communities of the country, there was no overt nation-state model in German Studies at that time.

It is hardly a surprise that the two world wars, with their huge impact on everyday life in Belgium, reinforced anti-German sentiments and to some extent even made sympathy for any aspect of German culture suspicious. During both occupations, the German military command had tried to instrumentalize Flemish activism, parts of which strongly sympathized with Germany and collaborated with 
the occupier, as an element of its political strategy and marginalized or even excluded university faculty who either ideologically or scholarly did not adhere explicitly enough to the occupational premises (e.g., those who had published on Jewish-German authors, such as Heine). Remarkably, many of the few scholars responsible for teaching German language and culture at the different universities paid attention to small-scale minorities in the German-speaking world, to regional varieties, and to countervoices in the German public sphere. Yet, even the fact that German became the third official language of the country in the early 1960s did not have a strong impact on the position of German Studies at Belgian universities. Except for a small part of the scholarly community (e.g., Ernst Leonardy at Louvain-la-Neuve, who did research on German-Belgian literature), German Studies was seen as the academic approach to a neighboring culture. Hence, for the largest part of its history as a discipline in Belgian academia, German Studies never really adopted a nation-state perspective.

Apart from the political and cultural circumstances, there were and still are institutional reasons for this as well. German Studies in Belgium have always been part of a two-language-model, both in the combination of linguistics and literary studies as well as in the applied linguistics curriculum. This gives scholars a strong comparative and contrastive stance. At universities in the French-speaking part of the country (ULB-Brussels, Liège, Louvain-la-Neuve, Namur), German Studies still are part of a "Germanic" curriculum, together with Dutch and English, whereas at Flemish universities (Antwerp, VUB-Brussels, Ghent, Leuven) everyone who studies German combines this with another European language. Dutchspeaking students benefit from the linguistic proximity of German to their mother tongue, on the levels of vocabulary, pronunciation, syntax, and word order; all their German Studies courses are taught in German. In French-speaking universities, even though they recruit a small segment of their students from the German-speaking part of Belgium, language learners take more time to develop a sufficiently high level of proficiency and usually get the first part of their education in their French.

In both parts of the country, the transfer of memories referring to the big twentieth-century conflicts appears to have stopped.The public opinion towards German, particularly among young people, has become less hostile; young scholars have developed a pan-European mindset and admire Berlin and Vienna as cultural metropoles. All Belgian universities have encouraged student mobility and exchange programs with German institutions, which above average welcome and accommodate foreign students, and there is a general public acceptance of Germany's political prominence in EU. This does not have a positive effect, however, on the number of the students in (academic or non-academic) German Studies programs, since the younger generations communicate increasingly in English as the common foreign language. As far as research is concerned, the academic agenda differs little from the focus in universities in German-speaking countries. In nearly every Belgian German Studies department, at least part of the faculty 
has German as its mother tongue; researchers tend to assume an intermediate position between the "Germanistik" as they know it in Germany, Austria, and Switzerland on the one hand, and international German Studies on the other. At the same time, the number of language learners taking German classes in high school has decreased vastly, both in Dutch-speaking (about one in five) and in French-speaking communities (approximately one in ten) (see Ceuppens/Gallez/Leuschner; Leuschner/Küpper; Lochtman/Obst). It is still unclear what this development will mean for the future of German departments, but that it will have an impact is likely-at some universities the effects have started to emerge and the compacting of curricula has begun. At the same time, neither the federal nor the regional authorities have actual control over research planning; it depends mostly on local and individual initiatives, sometimes (but not generally) across universities, although these are still subjected to the implicit and often involuntary bias of research subsidies.

As was already the case in the past, the nation-state paradigm does not appear in any way decisive for research. Inge Arteel at the University of Brussels (VUB) and the Österreich Zentrum Antwerpen (OCTANT) at the University of Antwerp, for instance, have developed over the years a strong Austrian focus, but with a particular interest in the multicultural (Habsburg) background of Austrian culture, whereas Antwerp also benefits from the historical Jewish community in the city to underpin its long-term commitment to researching German-Jewish literature and thought (Vivian Liska). Ghent and Leuven consist of a somewhat larger group of German Studies scholars and hence have managed to establish a broader perspective on linguistic and literary processes in German. Within German literary studies, Leuven focuses on the literary culture of the long nineteenth century and modernism, on German-language philosophy and drama (Bart Philipsen), and on cultural and gender diversity as well as minority cultures (Anke Gilleir). Ghent puts an emphasis on contemporary and encyclopedic literature, and experiments methodologically with rhetorical narratology, ecological fiction (Benjamin Biebuyck), digital scholarship, and literary disability studies in German (Gunther Martens). At French-speaking universities, we witness a sustained attention to Belgian-German cultural relations (Hubert Roland/Louvain-laNeuve) and Weimar classicism (Antje Büssgen/Louvain-la-Neuve), to intercultural exchange (Valérie Leyh/Namur), to autobiography and inter-art connections (Vera Viehöver/Liège), and once again to Austria's diverse literature and culture (Helga Mitterbauer/ULB-Brussels). Over the last decades, linguistics has become a more prominent division in German Studies curricula at Belgian universities, and achieved autonomy from language proficiency objectives.

If there have been any traces of a nation-state paradigm at Belgian universities with respect to Germany in the recent past, it must have been the awarding of an honorary doctorate to the German chancellor Angela Merkel jointly by the universities of Ghent and Leuven in 2017. This was however not an initiative of German Studies departments, but rather of the two universities' policy and deci- 
sion makers. Hence, we may conclude that German Studies in Belgium, for a number of different reasons, never adopted any nation-state paradigm, but always had a strong interest in linguistic and literary phenomena that are linked with minority cultures, linguistic margins, and the literary periphery. This is no surprise, since the basic cultural self-conception of scholars in German Studies in Belgium is deeply entrenched in liminality and transition between different cultural and language areas. This reinforces the encompassing attention to dynamics that transgress nation-state borders. At the same time, the geographical vicinity of Belgian universities to the German-speaking world and their relatively easy accessibility make it attractive for German-speaking scholars to apply for jobs and research opportunities in Belgium. This combination leads to either a globalist, intercultural approach or, on the contrary, to a strong focus on the local and the regional.

BENJAMIN BIEBUYCK

Ghent University

\section{Three Lessons about Germany}

My socialization into the profession of German Studies was conditioned by three factors, all of them connected to reflection on the nation-state model. First, I spent one year of graduate school in the mid-1980s studying at what was then called the Karl-Marx-Universität in Leipzig, in the German Democratic Republic. My experiences in Leipzig of a different way of constituting "Germanness," both in terms of the architecture of the East German state and also discourse about nationhood, made a profound impression on me.

Second, the 1980s, when I was in graduate school, were characterized by multiple discussions about the social constructedness of national identities, including, especially, German identity. For instance, in a highly influential 1989 special issue of The German Quarterly devoted to Germanistik as German Studies: Interdisciplinary Theories and Methods, Hinrich Seeba contended that "The Berlin Wall has come to symbolize in the most drastic form the illusionary nature of German national identity" (153). Seeba argued forcefully that the newly emerging German Studies approach to what had previously been called Germanistik should constitute itself as an "intercultural critique of identity formation" (151). In a similar but more psychoanalytically informed vein in the same issue of The German Quarterly, Sander Gilman suggested that German Studies should establish itself as "cultural criticism, the study of how a culture understands and represents itself-not what actually went on in the culture but what the culture wanted (or was unable to repress sufficiently) in representing itself" (193). Gilman strategically rejected the very concept of "Germany" as a national identity, replacing it with the term "the 
German." For him, "Germany" was a "political concept which may have validity for a mapmaker but not for a critic," while the plural form, "the Germans," destroyed "the nuances of social constructions like gender, class, 'race" (200).

In the shorthand of the time, the social constructedness of a concept such as national identity tended to be conflated with fictionality or non-existence. The implication was that once enough critics had seen through the fictionality of a social construction, it would disappear into the nothingness from which it had emerged, rather like the emperor's new clothes in the Hans Christian Andersen fairy tale. Admittedly, it was highly paradoxical for humanists, whether implicitly or explicitly, to take the position that social constructedness is tantamount to non-existence, and that only the natural world (for instance the world of biology, chemistry, or physics) has real existence. However at the time, the full ramifications of such a position were rarely reflected on (see John R. Searle's philosophically grounded reflection on this problem). At any rate, both Seeba's and Gilman's arguments, as well as many others, tended toward an insistence on national identity as "illusionary" and a definition of German Studies as uninterested in "Germany" or "what actually went on in the culture" and primarily focused on concepts such as "gender, class, 'race" that were perceived — whether rightly or wrongly—as mitigating or working against the false, illusionary wholeness of notions of German national identity.

Gilman heaped additional scorn on Germanists situated in North America who might seek to align themselves with colleagues in Europe. For him, American German Studies should constitute itself precisely through its differentiation from the profession as practiced in Europe: "How pathetic is it to see literary critics teaching at American universities, always marginally out of step with what is going on in the GDR, FRG or Switzerland or Austria, pretending they are in Munich or Graz" (192). Thus the new approach to German Studies was moving toward: 1) a critique of German national identity as illusionary or fictional; 2) a corresponding celebration of other identity categories, such as "gender, class, 'race"; and 3) an implicit or explicit separation from Germanistik in the Germanspeaking countries and an emphasis on North American scholarly independence. Of course the German crimes of the twentieth century, particularly World War Two and the Holocaust, contributed to the sense that German national identity was highly problematic and dangerous, and that it was the responsibility of scholars in North America to help combat such dangers. This responsibility carried with it an inevitable but under-theorized risk: a sense of American arrogance, entitlement, and superiority that authorized U.S.-based scholars to help "cure" Germans of their unfortunate illusions of national identity while applying analytical templates developed in North America to the European situation.

The third major factor conditioning my emergence into the profession was, unsurprisingly, the fall of the Berlin Wall, the collapse of the German Democratic Republic, and the reunification of Germany in 1989-1990. On the one hand, these events clearly showed that what had been received wisdom only a short time before could evaporate into thin air very quickly. After all, as late as June 
1989 no less an expert than the writer Peter Schneider-America's favorite "goto" authority on all things German-had insisted in the pages of the New York Times Magazine, i.e., in the newspaper of record, that "there is no 'human right' of German reunification and there will continue to be two German states." At the time, this was the received wisdom about the "German Question" on both sides of the Atlantic. For Seeba, meanwhile, in the spring of 1989, it was precisely the Berlin Wall that symbolized "in the most drastic form the illusionary nature of German national identity."

Did the reverse hold true? Did the collapse of the Berlin Wall symbolize in a drastic way the stubborn resistance of seemingly obsolete notions such as German national identity? Was it possible for mental and social constructions to endure even as a supposedly insurmountable and irrefutable physical barrier collapsed? For me as a young Germanist just entering the profession in 1989, the discourse and events of that year created a kind of scholarly whiplash effect. On the one hand, academic discourse tended to reject and even condemn notions of national identity, celebrating instead concepts of globalization, hybridity, and marginality. Indeed, the rejection of German national identity might have formed part of a new dictionnaire des idées reçues for German Studies in the 1980s and 1990s. On the other hand, and confusingly, on the streets in Leipzig and elsewhere actual Germans on the other side of the Atlantic were shouting, "Wir sind das Volk!"

Ultimately the revolution in the GDR brought about the collapse of the East German state and, in quick succession, the disappearance of the entire East bloc, the dissolution of the Soviet Union, and the end of the Cold War system. As a young German Studies scholar at the time-one who had spent a formative year living in an apparently permanent East Germany only a short while earlier-it seemed to me self-evident that it was my responsibility to take into account what was actually going on in Germany, and not to pretend that empirical reality in the German-speaking world should have no impact on a pristine and no doubt well-meaning theory about the illusionary nature of German national identity. Otherwise I feared becoming rather like the residents of the fictional island of Laputa in Jonathan Swift's satire Gulliver's Travels: intellectually unmoored from actual physical reality and freely floating in the air, with no concept of how to live in the real world. To me, entering the profession, it seemed self-evident that German Studies should actually contribute to the understanding of the real-existing country of Germany and its culture. This did not, of course, imply slavish emulation, lack of criticism, or acceptance of social constructions as unchangeable and permanent; but it did mean that scholarly theories and interpretations should take into account the situation in the German-speaking world, however evanescent and changing such situations might be. Likewise it seemed to me, given the whiplash effect caused by the events of 1989 , that it was incumbent upon German Studies scholars to treat their findings as provisional and always open to potential revision, rejection, or improvement. In other words, theory should be informed and corrected by the empirical world, not unmoored from it. 
Of course the situation in Europe and in German Studies has changed since 1989-1990, and Germany is now part of the European Union, while relations between the U.S. and the Federal Republic in the age of Trump are unfortunately more troubled and contentious than ever before. I believe, however, that the basic lesson of scholarly humility and caution that I learned three decades ago is just as relevant today as it was then. And Germany and the nation-state remain central to my scholarly practice.

STEPHEN BROCKMANN

Carnegie Mellon University

\section{Orientations in German Studies}

The nation-state has certainly provided an enduring framework for teaching and research in European literatures. In "German Literary Studies and the Nation," Jakob Norberg reiterates an old narrative in which an ethnonational mission consisting of "historical-genealogical linguistics, vernacular canonization, [and] national-literary historiography" was central to the establishment of our field in the nineteenth century (11). This narrative, Norberg asserts, it is not a relic from the past: everything we do today in German literary studies, in his view, must be mediated by the ethnonational paradigm in order for the field to maintain its coherence and, ultimately, to survive (1-2).

Even though Norberg recognizes that the field has changed since its inception, the structure and main focus of his article and recommendation leaves out many innovative approaches, and it disenfranchises many people whose lives were and continue to be touched by the German language within and beyond the nationstate. Norberg's manner of storytelling, namely paying more attention to the nineteenth-century tradition rather than to its critiques ever since, is unquestionably a political act. Sara Ahmed writes in Queer Phenomenology that the "work of repetition is not neutral work; it orients the body in some ways rather than others" (57). If we apply Ahmed's words to the context of Norberg's article, we have to ask how our orientation to the canon "allows us to expose how life gets directed in some ways rather than others" (21), and how "it [points] toward some bodies rather than others" (31). Granted, Norberg anticipates this question in the last third of his essay. He concedes that not everyone spoke or speaks German in the countries in which German is the official language and that the ethnonational philological project is exclusionary in terms of its Antisemitism. Nevertheless, he seems undeterred. In his view, we need the ethnonational paradigm to comprehend what we study as well as to maintain political power as departmental units at our institutions. We and our students need the benefits provided by national funding programs and exchanges. Be that as it may, by repeating the story of 
Herder, the Brothers Grimm, and their like, the article does not capture how many people in our field are oriented today.

Forum contributions that have appeared in The German Quarterly since the 1990s by Katharine Arens, Nina Berman, Claire Kramsch, Sara Lennox, Paul Michael Lützeler, B. Venkat Mani, Jeffrey M. Peck, Frank Trommler, and others illuminate our field's sustained interrogation of the philological canon established by the German cultural elite. For example, an examination of "Forum: Feminism in German Studies" (Loentz) that appeared in the issue immediately following Norberg's essay demonstrates that feminism, queer theory, critical race theory, and intersectional analysis are thriving in our field (GQ 91.2: 202-27). Tiffany Florvil points out in this forum how feminist intellectuals of color working inside and outside the academy have shaped debates in the field and thus help reorient us to questions that might otherwise be overlooked (228). Some of these questions include sophisticated analyses of colonialism, Antisemitism, racism, homophobia, and Islamophobia, important issues that cannot be fully explained with the ethnonational context Norberg promotes. Along these intersectional lines, the work of Regine Criser, Ervin Malakaj, Amanda Randall, Kathryn Sederberg, and many others working in the Diversity, Decolonialization, and the German Curriculum group helps maintain a sustained critique of the nation-state's violent forms of oppression and gives a voice to those in the profession and to our students who are dedicated to social justice (see "Open Letter"). Indeed, the field of German Studies goes beyond ethnonational conceptions of philology and literature in order to explain our complicated and interconnected world.

I am inspired by these scholars and incorporate their insights into my work, thereby changing my orientation toward German Studies. As a scholar of nineteenth-century German literature who investigates how literary and print media intersect with the history of visual culture, literature is not my exclusive object of study. Admittedly, the nation-state model has been a productive way to think about the history of the book, panoramas, photography, and the cinema. Many books on media history were and are still being written with single nations and with single inventors in mind. We orient ourselves toward Johannes Gutenberg's movable type instead of much earlier developments in East Asia. Or we fail to take into account the more complicated stories about the groups of people from around the globe who had been experimenting with techniques for capturing images on substrates with light and chemicals before and concurrent with Daguerre. When we publish on the history of graphic narration and teach courses on comics, why don't we write and teach comparative and global comics history that accounts for colonial and liberal forces at play in the medium's production and reception in France, Belgium, Switzerland, Germany, Austria, North America, as well as Israel, Japan, China, India, and Malaysia?

As an alternative, I would like to suggest that we all should research and teach so that we question "methodological nationalism" (Conrad 37). This means that we should highlight how unequal networks of power, volatile flows of people, 
materials, and capital, as well as unexpected entanglements reflect historical processes on the local and global level. If we do not do so, we will miss opportunities to think about the proliferation and circulation of media as part of larger global processes. And if we do so, we might include philosophical and theoretical frameworks from fields outside of German Studies. Our work will be meaningful to more people as a result.

Finally, and perhaps most importantly, I would like to stress that the ethnonational paradigm will not save our discipline. First and foremost, we must be excellent teachers if we want German Studies to flourish and our work to have an impact. We must foster our students' curiosity and embrace their multiple orientations. At least this is what I try to do at the small liberal arts college where I work. Our students come from many places and decide to speak German for many reasons. It is undeniable that some enjoy reading, discussing, and writing about canonical literature and philosophy. Yet others enter our classroom and discover the work of W.E.B. Du Bois, Audre Lorde, Angela Davis, Yoko Tawada, Feridun Zaimoğlu, Sharon Dodua Otoo, Barbara Yelin, Jean-Ulrick Désert, or Tony Miyambo. And some may see the Jewish Museum back home in Shanghai with new eyes and decide to learn more about the history of German-Jewish refugees. There is the student who decides to do off-campus-study both at a historically black college and in Berlin. Her choice is not odd, she learns. On the contrary, she is joining a tradition of intellectual and cultural exchange experienced by Germans and African Americans in the past. A student from Chile and Ecuador who holds a German passport but never spoke a word of the language before he came to Iowa decides to translate English- and Spanish-language poetry into German. While many discourage him from this undertaking (only native speakers can translate into German, so the story goes), he persists and learns to question the usefulness of the native-speaker and national paradigms.

Granted, it is difficult at times to break ties with the nation-state. The German embassy, our professional organizations, many textbooks, and promotional materials for study-abroad programs reinforce this model. What matters to our students most is that we care, and that we listen to them. Students take our courses because the faculty in smaller departments give them the attention they need for their intellectual and personal growth as well as practical advice they may not find elsewhere. Outside of the classroom, we work to enhance the student experience. We meet with students of color in office hour, attend student drag shows, and serve on committees to develop administrative policy that supports initiatives that affect the entire campus community.

If we orient ourselves toward the entire student rather than focus on the transmission of a particular national intellectual tradition, we might make considerable strides in improving our situation in higher education. It is undeniable that the field of German Studies is a white space for many students at colleges and universities (cf. Anderson, “The White Space”). The number of people receiving our field's highest terminal degree does not represent the diversity of higher educa- 
tion. Among all the 54,664, doctoral recipients in the US in the year 2017, 72 individuals received a $\mathrm{PhD}$. in Germanic Languages and Literatures. Out of these German PhD. holders, 3 reported to be Hispanic or Latino, 1 American Indian or Alaska Native, 1 Asian, 1 Black or African American, 2 other race or race not reported, and 1 other ethnicity or ethnicity not reported (National Center for Science and Engineering Statistics / NSF 19-301, "Table 22. Doctorate recipients, by subfield of study, citizenship status, ethnicity, and race: 2017”). This fact has been registered by our field's journals on more than one occasion. John Long addresses the lack of access to instruction in German on the secondary-school level in low-income minority communities (GQ 73.1:19-20). Likewise, George F. Peters writes that more black and Hispanic students have access to higher education, and yet there are few people of color standing in front of these students in our classrooms (UP 25.2: vii-viii).

Robert C. Holub warned that "[w]e continue to operate with this superannuated paradigm [philological studies] at our own peril" due to new bodies enrolling at universities (GQ 80.1:101-02). In "Talking Race and Racism," bell hooks observes that we are hesitant to acknowledge "the extent to which white-supremacist thinking informs every aspect of our culture including the way we learn, the content of what we learn, and the manner in which we are taught" (25). I am not arguing for opportunism, a way to increase our enrollments in a period of decline and departmental closures. Instead, I am arguing for a pedagogy informed by feminist practice. This intellectual framework and pedagogy will help our students orient themselves and find within this vast field of knowledge what excites them. VANCE BYRD

Grinnell College

\section{Considering a Nation-Critical Model}

When reading contemporary German literature, it is hard not to conclude that the nation is, above all else, an institution of trauma. The nation has waged war and genocide, decimating families, but also destroying memory and even the ability to tell stories. In Katja Petrowskaja's Vielleicht Esther (2014), for example, the narrator attempts to piece together her family history by visiting the sites where family members were murdered between Berlin and Kiev under National Socialism. Her attempt yields further uncertainty, the "vielleicht" of family history after genocide. As a political entity, the nation marginalizes and excludes. In the beginning of Christoph Hein's Landnabme (2004), the reconfiguration of the German map after the Second World War leads to the displacement, social marginalization, and trauma (represented through speechlessness) of the young Ostsiedler Bernhard Haber. His life work is the project of finding a way to belong. 
As an anchor of identity, the nation can traumatize when it disappears. The dissolution of the GDR in Jana Hensel's Zonenkinder (2002) leads to the narrator's feelings of inadequacy in the newly unified Germany. In Terézia Mora's Alle Tage (2004), the traumatized Abel Nema has no sense of identity after the dissolution of his nation, a Balkan country that no longer exists. Stateless and living precariously as a refugee in Germany, Abel lacks a sense of self anchored in a location. Conversely, the nation can trap an individual into forced belonging, as in Abbas Khider's Derfalsche Inder (2008). After Rasul flees Iraq, a nation of arbitrary imprisonment and torture under Saddam Hussein's regime, and then Greece, the nation that perpetually threatens to send refugees back into danger, he becomes stuck in Germany, the country that obstructs his journey to Sweden because of its asylum laws. Taken in sum, the nation, framed as a source of trauma in contemporary German literature, is an important development; a generation prior, German literature was much more occupied with questions of guilt and repressed memory when it came to issues of the nation. (That is not to say that other voices and other concerns weren't pertinent at the time; they merely received less attention.) The nation as a source of trauma is now a central discourse that results from a proliferation of voices having come to the fore in German literature in the twenty-first century-what Anna Fuchs and Mary Cosgrove have termed the "memory contests" in contemporary German literature.

When I teach my students about the historical circumstances of nation building in the nineteenth century, we talk about the central question of the nation: "Wer gehört dazu?" with the implied correlative question "Wer nicht?" Framing the nation in this way helps the students understand the rise of anti-Semitism during the Romantic period and again towards the end of the nineteenth century, important moments in nation building. The nation as a concept, as a political entity, is inherently exclusive. Who belongs, who doesn't, who can stay, and who can't is its perennial concern. Literature and language, I hope, have the potential to be more inclusive and to invite identification in more ways than the political entity of the nation tends to do, as the recent proliferation of voices represented in German literature attests. The grandmother of Jenny Erpenbeck's protagonist in Aller Tage Abend (2012) reaches for her volume of Goethe's works as her family moves to Vienna after surviving pogroms in Polish Galicia at the turn of the twentieth century. By reaching for her Goethe volume, she demonstrates her attachment to the German-language literary heritage when the political entities that govern her life wish to expel her. Toward the end of the novel, the reader recognizes the protagonist's son's mistake when he selects a decorative plate picturing Wilhelm II and Franz Joseph as a gift for her instead of the very same volume of Goethe's works that belonged to her family and has ended up in an antique shop. Literature was a touchstone of cultural inclusion for his greatgrandmother when the political nation excluded her.

It is important to recognize that both the exclusionary nature of the nation and the potential for inclusiveness in literature exist at the heart of German Stud- 
ies. The history of our discipline is undeniably entwined with the project of the nation and has, for the length of its existence, harbored a sometimes latent, sometimes explicit, ethno-nationalism. As members of the Diversity, Decolonization, and the German Curriculum Collective have pointed out recently in an open letter to the AATG, we must face the fact that our institutional make-up is largely white; we are in dire need of overcoming the exclusionary tendencies of our nation-based discipline. It is tempting to seek a way to abandon the nation-based model altogether after recognizing in it the exclusionary, traumatizing practices of the nation. What would it look like to abandon the model we now have? Would that mean a decentralized German curriculum? How could the study of German languages and literatures thrive on a campus that didn't have a German department or a German section within a larger Modern/Foreign/World Languages department? Or could we retain German departments/sections, but somehow divorce them from the nation model?

Like many other programs across the country, the German section at Kansas State University, my home institution, has made attempts to work with other units on campus in order to prove our relevance in the current era of budget cuts. We engage in discourses on the increased hiring and earning potentials of students with a second language. We teach Business German and are considering developing a "German for the Professions" course. Our Composition and Conversation courses focus on language skills and "practical writing" rather than strictly on cultural or academic content. Yet as a colleague recently reminded me, these professionalization courses still rely on the concept of the nation. Business German is, in effect, a course on how to behave in a culturally sensitive and culturally effective manner, and how to "belong" in the professional arena in Germany. My fear is that in our efforts to make these connections across campus, in foregrounding skills over cultural content, we will lose the heart of what we do, the humanities focus. To draw on the example from Erpenbeck above, I don't want us to miss the Goethe anthology and select the decorative plate instead, undervaluing a difficult but also rich cultural heritage for a representation of Germany that is more easily accessible to others.

I suggest that instead of abandoning the nation model, we accept the nation as the basis of what we do, but in a more self-aware and self-critical nature than we have done before. I suggest that we build a nation-critical German Studies that connects with other units on campus and other fields in our research. A nation-critical German Studies does not take the nation as self-evident or a fixed object of study, but as a construct that has been traumatic, exclusive, and fragile. It teaches that "Germany" has always been double or multiple in its political structure- as the Deutscher Bund, in the duality of monarchy and representative government, Germany / Austria, East / West, Germany / EU—and multiple in its cultures. It teaches that the ethno-centric narratives that inform the dominant image of German-speaking lands is inaccurate, as Jewish people, Muslims, Africans, people of color, trans and gay people, have always existed alongside and 
within the heteronormative white culture that has had the privilege of representation. It investigates how the exclusive nature of the nation-construct has shaped and limited the voices present in the literary cannon, and it works on developing diverse representation in textbooks. A nation-critical German Studies does not teach exclusively within a German department or section, but cross-lists with other departments like Gender and Sexuality Studies and Film and Media Studies; it teaches freshmen seminars and humanities surveys that critically examine the hegemonies of the nation, and it fights for more funding on campus so that we can teach those courses. It takes measures to mentor students of color so that they can see a path in our profession. Finally, to build a less insular nation-critical model, our research and publishing must be more collaborative and interdisciplinary. We can work with other disciplines to address problems that the nationstate presents - trauma, memory, exclusion, migration, war, genocide — and we can publish those collaborative and interdisciplinary works in venues that serve disciplines beyond German Studies. Engaging critically with the problems caused by the nation, paying special attention to the voices coming through in literature, and inviting dialogue with other academic disciplines and units may be the best way to preserve the heart of what we do while also demonstrating our relevance and our willingness to move away from the exclusionary practices of the nation. NeCIA Chronister

Kansas State University

\section{An Approach both Global and Pragmatic}

With seventeen years between the dates when we were awarded our respective $\mathrm{PhDs}$, we represent two generations of teacher-scholars. Yet neither of us is beholden to the idea of the nation-state in her scholarship. The texts at the center of our research are, of course, connected to the German language and looselydefined German spaces. Yet if there is a container for our work, it is "German" as an adjective and not "German" as a synecdochical noun, as the part that constitutes the whole of our subjects.

This approach is particularly useful when engaging with texts by and representations of those who have been excluded from or exist in the margins of both statesanctioned institutions of power and the German canon: persons of color and/or without ethnic German ancestry, LGBTQ+ persons, disabled persons, migrants into and German speakers living outside of the borders of German-speaking nation-states, and women. It also recognizes the interdisciplinarity that has marked the humanities for some time now. While "German" is one marker of the "studies" that we pursue, our research is also at home in Gender Studies, Global Studies, Human Rights Studies, and the Scholarship of Teaching and Learning. 
German Studies does not require research that focuses on the nation-state in order to survive into the future. To understand this, we need only to turn to our colleagues in English departments, some of whom study literature, film, and other texts from around the globe, mostly in English translation. The concern for us is not German Studies as a discipline but German programs at post-secondary institutions. For these programs to continue into the future, we need three things: 1) students, 2) articulated curricula emphasizing the development of language proficiency and intercultural competence from start to finish, and 3) engaged and pedagogically informed tenure-line faculty teaching at all levels.

It is no secret that German enrollments are declining, and while there are many reasons for this, one cause is the failure to ask who our students are and what they want. Our current students were born in the shadow of $9 / 11$ and are coming of age in a world of rapid climate change. They are affected by global movements and migration. Many are concerned about a lack of equity and inclusion at home and abroad. They are paying ever higher sums for educations that may not lead to jobs but often lead to massive debt. Neither they nor their parents are swayed by traditional arguments for a humanities-based education: that it will improve their critical thinking skills, make them more empathetic, and turn them into better citizens. They are asking, quite loudly, about the relevance and usefulness of German Studies. This doesn't mean that they don't care about language, literature, and culture- just that they want to know what these things mean, and, whether we like it or not, what value they have. If we cannot answer our students' questions, they will seek out programs that do. And because our answers will differ depending on the students at our given institutions, we should be listening to them-as well as each other-in search of new ideas.

At our urban, public, research-1 institution, many undergraduates in German double major across disciplinary fields, and most of our graduate students seek jobs outside of the academy. The more pragmatically minded seek competencies that will help them find jobs at international companies, or live in a Germanspeaking country. The more idealistic seek answers to a basic question of the humanities-what does it mean to be human?-as offered by a culture and language other than the one(s) they know from their lives here in the U.S. It is unlikely that any of our students would buy into a program focused on the cultural underpinnings of the German nation-state. They come to us to develop their German proficiency and intercultural competence through our classes, our Junior Year in Munich program, and other study abroad opportunities. These skills help them to pursue professions in Chemistry, Education, Engineering, Global Supply Chain Management, Information Science, Law, NGO-work, Psychology, Publishing, Teaching, and Translation. At the same time, they contribute to the quality of graduates' lives and help them to become critical thinkers and more empathetic human beings.

German language training and the development of intercultural competence (based on the model of engagement with "German" culture/s) also happen to be 
what makes German Studies programs unique. Minus these two key elements, we could just as easily do our work in English or History or any number of interdisciplinary programs. If we want to strengthen German Studies, we must articulate our programs around proficiency, intercultural competence, and the needs of the students and strengths of the faculty at our particular institutions. Fortunately, we can consult ACTFL and CEFR guidelines here.

Unfortunately, our two-tiered systems continue to grant secondary status to colleagues with expertise in pedagogy and intercultural competence, thereby contributing to the disregard for language learning so endemic in the U.S. The scholarship of these colleagues is undervalued. Program directors, even in the few instances when they have tenure, rarely find colleagues willing to help articulate programs according to proficiency goals. Many program directors are lecturersoften women - with higher teaching loads and less respect than their tenure-line colleagues. This, although their work is largely responsible for encouraging students to become the majors upon whom the future of our programs relies. If we do not grant these colleagues equal status, if we do not work with them to build programs that foreground proficiency, intercultural competence, and student needs, we will continue to lose ground. (See also Michael Bérubé and Jennifer Ruth on how this affects academic freedom in general.)

What if we accept the "German" in German Studies as an adjective that opens up our field to a wide range of disciplines and a wide range of questions posed to "texts" that are loosely connected by language and/or geography? And what if we accept that, to ensure our future, we need students in our classes, program articulation that centers on language proficiency and intercultural competence, and the opportunity for all faculty to achieve tenured status? Making these moves untethers German Studies programs from the national-languages model and opens the door to new models for the institutional organization of our work.

At Wayne State, the programs that currently constitute "Classical and Modern Languages, Literatures, and Cultures,"were merged together from above. This is not a unique situation. Our chair took control of the situation, however, by working with faculty from across campus to develop a Global Studies Major and Minor within our department. The major requires intermediate language proficiency in one language or novice-high proficiency in two. Lisa developed the template for the humanities-based core course, Global Stories. Nicole designed a core course on Intercultural Competence. Both are highly popular because they allow students to explore issues that are important to them: comparing their perspectives with those of others, exploring how perspectives, values, and practices change over time, discussing globalization's impact in the past and the present. Global Studies has also benefitted German by helping us to rethink the German major and minor, which we redesigned so that Global Stories and Intercultural Competence can fulfill two of our three English-language requirements. We also find that the content of the courses we teach in German increasingly addresses issues of global relevance. 
It is easy to imagine ourselves developing further in this direction. Global citizens need an appreciation of the diversity in the U.S. and abroad, as well as concrete intercultural competencies that help them both to understand themselves as cultural beings and to navigate the globe. Such skills, attitudes, and knowledge can become a signature of German Studies as an interconnected, global discipline. Some departments have already made this move. University of Alberta faculty established a B.A. in Modern Languages and Cultural Studies that allows students to choose between language-studies and cross-cultural-studies routes. King's College London launched a new M.A. in Modern Languages, Literatures $\&$ Cultures that similarly thinks of specific languages in connection and exchange with others. This reflects our changed world with its transnational networks and supranational organizations-as well as the regional variety that exists in every "nation"-much better than any isolated language study ever could.

While questions about the German nation-state might serve as the anchor for some German Studies programs, they are not at the center of our research or our teaching. Nor are they the questions in which our very diverse students here at Wayne State are interested. German Studies does not need the nation-state model. Rather, it requires openness to multiple models and multiple ways of thinking and an understanding of who our students are, along with commitment to language proficiency, intercultural competence, and equal professional standing for all faculty.

Nicole Coleman and LisabeTH Hock

Wayne State University

Expanding the Nation-Thoughts on moving German Studies forward in the Twenty-First Century

In "German Literary Studies and the Nation," Jakob Norberg proposes that German literary studies must continue to rely on a nation-state model if it is to continue to exist. Norberg focuses primarily on language, noting that German literary studies "could not survive as an enterprise of teaching and research if the 'German' element were somehow to lose its centrality or be done away with entirely as a category - which means it cannot disentangle itself from the national paradigm that infuses its very existence with meaning" (13). At the same time, he appears to acknowledge that the paradigm is shifting: recent expansions within the discipline of German Studies "help create a German literary studies that appreciates the international, transnational, subnational, and suppressed anti-national aspects of culture, which are undeniable products of the national paradigm" (13). Others such as the Eaton Group address the value of "linguistic pluralism" (19), the role that multilingualism plays in German society today, and the merits of multilin- 
gualism for second language acquisition and language teaching pedagogy. These two viewpoints draw attention to tensions subsumed in the term German Studies. On the one hand, there is the tendency to conflate "German" with Germany, the nation, which leads German Studies down the path to the study of Germany. On the other hand, understanding German Studies as studies that involve the German language breaks the bonds of a territorial standpoint in favor of contextualizing the interactions between German and other languages. The impacts that the ravages of war and economic and environmental strife have had on non-Western nations, leading to the refugee crisis in 2015 , and forcing Western democracies to confront an influx of refugees, asylum seekers, and migrants, also has precipitated a (cultural) transformation of German society. Moving forward, German Studies must also transform itself by strengthening attention to (inter)cultural competence as a precursor for understanding our rapidly changing world. Such disciplinary change will take place on an international level. However, the way in which institutions across the United States are able to articulate this disciplinary metanarrative ultimately is dependent on local, institutional contexts.

At publicly funded institutions, particularly those institutions where state support has decreased precipitously for decades, German Studies programs occupy a precarious position. As Costabile-Heming and Halverson (2015) note: "the humanities $[\ldots]$ have been especially susceptible to hasty reactions by administrators regarding program and class size, cost of instruction, and limited external research funding" (1). Enrollment instability is clearly documented in the MLA's 2016 enrollment report, which recorded a $9.2 \%$ drop in overall enrollments in languages other than English from fall 2013 to fall 2016 (Looney and Lusin 2). While German enrollments experienced an overall decline of 7.1\%, $47.1 \%$ of German programs reported either stability or growth (Looney and Lusin 3). In 2003 John McCarthy noted that over the course of 125 years, the academic German department repeatedly has encountered challenges and weathered numerous transitional periods. In light of ongoing enrollment volatility, this continues to be true today.

Different types of institutions have different curricular and programmatic needs and expectations. There are variations in general education programs and liberal arts distribution requirements, as well as different requirements for the German (Studies) major. Some rely heavily on literature, while others take a broader and more interdisciplinary approach incorporating film studies, linguistics, and cultural studies along with a host of others. Some programs have course offerings only in German, others incorporate courses in English, taught either by the German faculty or by other departments. Furthermore, some German Studies programs exist as stand-alone departments, while others are part of foreign / world language / literature / culture departments. These contexts play a decisive role in curriculum development as well as in the relative autonomy of German Studies programs. In response to enrollment and budgetary challenges, German Studies colleagues across the US have become increasingly entrepreneurial in their efforts to sustain and grow the numbers of students studying and 
majoring in German. Nonetheless, declining numbers of precollegiate German programs mean that fewer college students enroll in German with prior knowledge of the language. Thus, there is mounting pressure on faculty who teach introductory language courses to retain students beyond the initial language sequence and "grow" their own majors. In light of these challenges, the traditional and conservative nation-state approach seems limiting.

Kagel and Donahue (2015) argue for an expanded understanding of German (cultural) studies, one that follows a path similar to European integration (274) and focuses on the teaching of language, literature, and culture in their multifaceted, multiethnic, and transcultural contexts (274). Robert Menasse's 2017 prize-winning novel, Die Hauptstadt, provides an interesting metaphor for the approach that Kagel and Donahue advocate. Menasse's capital is contemporary Brussels, seat of the European Union. The novel presents a broad cast of characters from diverse EU member states and critiques the rampant bureaucratic infighting that occurs as the characters seek to score the most benefit for their individual nations throughout the policy-making process. On one level, the novel is a psychological study of individualization, as each of the main characters focuses primarily on creating his or her own profile, in order to stand out among the many diplomats and assistants that make the EU function. On another level, however, the novel brings to the forefront the very issue that we are discussing here. While the EU is imagined as a broad union of member states and moving increasingly to governance at the union level, individual states struggle to maintain their identity, which, it should be noted, was a key reason in the United Kingdom's vote to leave the EU. Menasse's novel shows quite pointedly how national interests hinder working for the good of all member states. A case in point has to do with the swine industry and the EU's inability to strike a trade deal with China. A primary reason for the EU's inability to barter a deal has to do with the fact that individual states are signing their own treaties with China. No nation wants to be left behind; no nation is willing to allow its own interests to take a backseat to the interests of the $\mathrm{EU}$ as a whole. But what does this have to do with the status of German Studies today?

Like the tension between the needs of the individual EU member states and the greater vision for an integrated Europe, the nation-state approach to German Studies assumes a shared ethnicity that no longer is relevant today. Literary texts are coded as part of a national literature based on a variety of criteria that include social, political, economic, geographic, cultural, ethnic, and other factors. This coding of national literatures has become increasingly problematic as the physical global migration of people as well as the digital global migration of texts and text production has increased steadily through the late twentieth- and now the twenty-first centuries. Contemporary German literature reflects and problematizes this. Novels such as Jenny Erpenbeck's Gehen, ging, gegangen (2015) call the idea of nation and Heimat into question. Moreover, Erpenbeck points to Europe's historic role as colonizer, citing a continental complicity that has allowed colonial ideologies of race and ethnicity to continue to determine countries' economic and 
political status. In Eure Heimat ist unser Albtraum (Aydemir and Hengameh, 2019), twelve German-speaking writers tackle aspects of existential marginalization in Germany. These German-speaking writers add a new dimension to German language and literature, representing a paradigm shift in the way we think about monolingualism and multilingualism. In Beyond the Mother Tongue (2012), Yasemin Yildiz recontextualizes the way that Eurocentric thinking approaches questions of identity through language. Traditionally, monolingualism, the "mother tongue," demarcates ethnicity, culture, and nation (Yildiz 2). Linking language to ethnicity makes discrimination and exclusion possible (Parry 121), and this is precisely what the authors of Eure Heimat ist unser Albtraum attempt to make visible. The circumstances they describe are not unique to Germany, but represent instead universal experiences that are a part of German culture and society today. Given their timeliness, such texts have the potential to speak to the current generation of college students in ways that canonical texts cannot. As borders have become more fluid, the idea of what is German or perhaps more specifically where is German increasingly has less to do with geographic borders and much more with broader aspects of identity. This emerging trend has the potential to have significant ramifications on the way university departments are organized. In fact, I believe it has the potential to lead to greater collaboration and interdisciplinary engagements.

How individual German Studies programs respond to this latest transformation of our discipline ultimately will depend on the resources, support, opportunities, challenges, and unique climate of individual campuses. In all cases, though, language should remain the cornerstone of the curriculum. If a programmatic goal is to help students to decode and understand texts that are written in German, faculty can accomplish this goal either through texts from the traditional canon or with less canonical voices. Institutional contexts preclude a uniform German Studies curriculum and influence greatly how German Studies is practiced in the United States. One thing remains clear-without students enrolling in our classes, German Studies will not survive. Traditionally, language curricula have enforced a divide between form (language) and content (literature, culture), whereby lower level classes focus on the acquisition of vocabulary and grammar. Only after students have mastered the form, can they adequately access content, which is then introduced in advanced-level courses. Ideally, however, form and content are taught continuously throughout the undergraduate curriculum. As the Eaton Group states: "To truly accomplish learning that embraces the linguistic, cultural, and social, form and meaning must be connected at all levels" (27). If we embrace the connection between form and meaning, we can move beyond the nation-state paradigm, and introduce our students to interesting and relevant content that connects to universal experiences. For my own institution in Texas, where the chatter about borders and walls is nearly incessant, the universal experiences that contemporary German-speaking writers are grappling with have the potential to speak to nonGerman-speaking populations experiencing their own feelings of disenfranchise- 
ment. Using these contemporary texts and contexts, I aim for my curriculum to expand the concept of German Studies beyond the nation-state paradigm, and thus propel our discipline forward in the twenty-first century.

Carol Anne Costabile-Heming

University of North Texas

\section{The Nation as an Indispensable Construct and its Pitfalls}

For my professional career not just Germany (and Austria and Switzerland) but also another European nation-state, Ireland, has been important. The ability to look at German-speaking countries from the outside (from a place with its own long tumultuous history of forming a nation-state) enabled a broader picture. My views of German and its place in the world were shaped by a number of international experiences, notably teaching German at four schools (both Protestant and Catholic) in Belfast, Northern Ireland, my time as a graduate student at Washington University St. Louis, lecturing at the University of Otago in New Zealand, and most importantly my work at the University of Limerick in Ireland since 1996, where together with my colleague Joachim Fischer I founded the Centre of Irish-German Studies in 1997.

German Studies in Ireland in the 1990s experienced an unprecedented period of growth which built on an almost sevenfold increase in student numbers taking German for their final exams (Leaving Cert) in high school from 1,701 in 1985 to 11,430 in 1995 (Fischer/Schewe 1472). This dramatic increase was a response to a long period of economic problems and high emigration in the 1980s and a subsequent enthusiastic embrace of the European project. In 1992, almost seventy percent of the population voted in favor of Europe in the referendum on the Maastricht Treaty, which facilitated greater European integration and the formation of the European Union. While German Studies in Ireland was then (and still is) predominantly literature- and cultural studies-oriented, with linguistics playing a lesser role, Business German and combinations of German and law or engineering experienced a strong uptake. Further strengths of German Studies in Ireland have been pedagogy and cultural studies.

One of the new developments to which we in Limerick have contributed was an increased focus on contrastive cultural studies, analyzing the connections between Ireland and the German-speaking countries. This focus has illustrated how changeable and complex international relations are, how fluid and fraught the complex system of state, institutional, and personal relations, influenced as much by perceptions and prejudices as by historical and cultural contacts. The rather critical approach towards nationalism and a strong awareness of the potential hubris of nation-states, that came quite naturally to those growing up in Germany 
in the 1970s and 1980s, came up against a rather uncritical and strongly developed sense of national pride in Ireland that was a response to a long history of foreign domination and colonization. Terminology and concepts therefore need to be carefully negotiated to leave space for different experiences, without wanting to gloss over the dark side of German history.

The main focus of the Centre for Irish-German Studies at the University of Limerick is in the areas of culture and literature on the one hand and historical and political topics on the other (though collaborations with science, engineering, and business have also been productive). While the concept of the nation-state can be challenged in cultural and literary contexts (indeed, literary approaches allow us to imagine alternative histories and question and go beyond the nationstate construct), there is no doubt that it has been a defining term in the discussion of historical and political developments. In the context of Irish-German Studies, concepts derived from imagology and histoire croisée or Verflechtungsgeschichte (i.e., an entangled history that keeps in mind the interconnectedness of all nation-states) have been helpful in ways that go far beyond Irish-German (Irish-Austrian and Irish-Swiss) perspectives; to a large extent it is a European framework that comes into play here. To conceive of these links in a European context allowed us to go beyond the nation-states. However, the European Union's supranational structure clearly has also caused tensions and fear in sections of the population who feel threatened in their identity by the loss of national sovereignty and greater integration, thus giving rise to a growing nationalism. Irish-German relations have never been more important, especially in the past three years, not least thanks to Brexit. Both governments are more interested in one another than ever before. This has also had positive repercussions for German Studies as the Irish government is increasingly interested in facilitating and supporting the learning of foreign languages, specifically German, and has published ambitious aims of increasing the uptake of modern languages in the form of Languages connect-Ireland's Foreign Languages Strategy in Education 2017-2026. This welcome initiative to "heighten awareness of the importance of learning foreign languages" in order to "motivate more of our learners to embrace this opportunity with enthusiasm and enjoyment" (5), includes specific aims to increase the number of students at university level studying a foreign language, in any capacity, as part of their course. The need for such a strategy had already become obvious with falling numbers of language learners at universities fueled in part by the "Celtic Tiger," the Irish economic miracle from the mid 1990s to the late 2000s, when employment opportunities were plentiful.

The topic of speaking and learning languages is in fact very closely linked to questions of the nation-state in Ireland where English and Irish both have official status, with Irish being the national and first official language. The "Gaelic revival" played a significant role in the independence movement of the country. The Irish language requirement means that students will have to have Irish in their Leaving Cert when they apply to study at the National University. Efforts to promote Irish 
continue and often have priority, as evidenced by the publication of the 20-Year Strategy for the Irish Language 2010-2030 (2010) and the Official Languages Act 2003 (which requires the improved provision of public services offered in Irish, for example that all state forms, documents, and reports are available in English and Irish). The number of Gaelscoileanna, schools where all subjects are taught in Irish, is still rising, both at the primary and secondary level. Incidentally, German linguists contributed considerably to the academic study of the Celtic languages, a fact that is often recalled at mutual state visits of Irish and German politicians.

Integrating Irish-German Studies into the curriculum has allowed us to incorporate the personal backgrounds of our students and to discuss the negotiation of Irish and German identities at different times in history. It brings the individual and local to a larger binational and at times global level, as it teaches students not to investigate in isolation but to compare and reflect, for example in the context of immigration and emigration (the Irish national trauma since the famine). The concept of the nation-state is important for shaping the identities of the individual. In our teaching of German language and culture, we are therefore consistently dealing with underlying questions of "the other"-which can be exciting as well as frightening. Discussing individual motivations for language learning and pre-existing links between the respective home country (or countries) of our students and the German-speaking countries allows us to both individualize and transform our teaching from the exploration of something new and different to the exploration of the students themselves, and it introduces the possibility to experience diversity and personal and professional opportunities.

Engaging with topics such as the migration or marginalization of specific groups tends to be far more meaningful and yields more results if we are able to draw comparisons, and in many cases the nation-state-and in particular the differences of language, historical experiences, and cultural developments that can be connected to it-is a construct that enables us to do that. But things are of course rarely straightforward (an important lesson to keep in mind when thinking about the nation-state concept). Hans Mommsen stated already in the early 1980s that there was confusion about the concepts employed in discussions about the nation-state and national identities. To understand the concept better it may help to distinguish between two categories: first, the nation-state that exists as a current political entity regulating the daily life of its citizens through laws and providing educational and other organizational structures. This is something generally covered in Landeskunde and a subject that we need to explain and translate to our students, not least in order to enable them to successfully make a transition to living in a German speaking country during their study abroad period or at other times. Secondly, there is the historical and cultural construct which often includes an emotional dimension, of belonging or exclusion, and which can bestow a sense of home but also create tensions. In this context the exploration of imagined communities before and beyond the nation-state can be productive, as recent publications on the topic have shown (Kontje). 
The reality of the nation-state has received a lot of attention and has become much more meaningful in recent years, often with dangerous consequences. We are living in times when people from selected countries are, solely due to their nationality, excluded from entering the US. Closer to us in Europe, Brexit has shown that the nation-state is a construct very much alive, as is the fear of losing sovereignty. The rise of parties such as the Alternative für Deutschland (AfD) further illustrates the tremendous need to analyze nationalism and develop a critical and reflective vocabulary with regard to the nation-state. Thus any disengagement with the concept and its nuances and history is not an option-the nation-state model is an indispensable construct in German Studies.

Gisela HOLFTER

University of Limerick, Ireland

\section{German Studies, Neighboring Disciplines, and the Nation-State}

To understand German Studies today, it helps to look at Comparative Literature, a neighboring discipline perceived to be on the wane. A short generation ago, the lengthy Thomas Mann novel Der Zauberberg was one of the 200 or so works on a typical German language-culture qualifying exam in Comparative Literature, and every $\mathrm{PhD}$ candidate was responsible for three such language-culture-specific fields. Nowadays, a sense that output must expand even as time compresses has accompanied the so-called "visual turn" (see Berg and Seeber). Maybe partly for such reasons, undergraduate test takers struggle to make time to study featurelength films in their entirety. Another reason for the specific struggle of Comparative Literature, as part of a general downturn in the humanities, is the relative ascendancy of monolingualism among students, even in a nominally bilingual and rather migrant-rich country like Canada. Those who do not much worry about monolingualism point to the (current!) dominance of English and the time that language-culture-learning requires. Advocates of multilingualism for (student) Anglophones accurately point to cultural flexibility and cultural competence, earning power, cognitive health, agility and flexibility, and access to more of our world - and yet their perspectives do not drive policy (see Charbonneau).

The linguistic challenges of German departments parallel those of Comparative Literature. The move from Germanics to German to German Studies is seen as a necessary response to decreased numbers of students with command of the German language-culture and/or interest in taking the time to obtain it. Teaching in English aims to draw more students as a means of remaining relevant in the educational landscape and solvent in the corporatizing university. While this move exposes more students to "things German" and, subsequently, "things European" and "things transnationally German," it has furthered the tendency for even German majors to 
graduate with less proficiency than in decades past. The trend towards functional monolingualism is exacerbated in institutions with anemic language requirements and/or general education requirements. Finally, monolingualism blossoms under the pay-per-student budget models going into place throughout North America, recently in Ontario, that engender races-to-the-bottom as departments compete for students by decreasing the rigor of their curricula.

Something similar goes for another neighboring field, Cultural Studies. The monolingualism marking North American Cultural Studies seems largely unexamined and unapologetic. Perhaps this characteristic has to do with its origin in Britain, rather than the Frankfurt School or (East) German Kulturwissenschaften. To my mind, this reality curtails Cultural Studies' ability to achieve its aims of critical cultural analysis, as many scholars can only seriously engage English or imprecisely through translation. The increasing inability to function within multiple linguistic / cultural communities would hamper German Studies even more without the nation-state model, because the nation-state is significantly defined by (a) common language(s), with all the vicissitudes that this entails (see Gramling; Lennox).

Instead of disengaging from the nation-state, we should continue to expand its conception and explore its multiplicity. My 2004 dissertation that became Sun, Sex and Socialism: Cuba in the German Imaginary was part of a first wave of transnational German studies pioneered by scholars such as Sara Lennox, Susan Cocalis, Sigrid Bauschinger, Sara Friedrichsmeyer, Susanne Zantop, Nina Berman, and Arlene Teraoka. Some of these intellectuals were trained in Comparative Literature and historical materialism and may have felt constrained by the nation-state model. German Post-Colonial Studies (e.g., Susan Buck-Morss and Mary Louise Pratt) also encouraged re-thinking “Germany.” Transnationalism from "above and below" was shown to define Nation (see Lionnet and Shih). The de facto porousness of the German nation-state illustrates a global reality; Pratt's celebratory explication of US multi-linguistic and -cultural realities expresses the transnational lived experience of most of earth's inhabitants (see Pratt).

Growing up in European West Germany in the 1970s / 1980s, I don't remember thinking of the well-bounded nation-state as either descriptively or experientially accurate. For one, the Germanies always seemed obviously connected to their neighbors and infused with-even built upon-extranational influences. Coming out of the first phases of the Wiederaufarbeitung of its past, the 1980s Federal Republic featured a robust critique of the nation-state, which was seen as fertile ground for nationalism, colonialism, fascism, and neo-colonialism. On the left, the European Union offered great hope (see Habermas).

This supranational entity is increasingly contested today. Once imagined as a war-free zone of social provision and welfare, the EU is manifesting neoliberalism's glocal reach. Nationalism and regionalism are being wielded defensively as governments and citizens alike explore retreat to former polity iterations. However, transnational capital always has its boots on national ground where a coun- 
try's laws and protections are still valid and so governments can exert legislative and other forms of influence on corporations as well as on their nation's inhabitants. Despite extensive penetration of capital even in the public sector, citizens still have more impact on their governments than on supranational governance structures or corporations; the contract between nation and citizen mandates not only governmental monopoly control over legitimate violence but also governmental defense of rights and freedoms. Within today's fraught geopolitics, nation-states remain powerful and their citizens hold power in and through them. Thus, it is incumbent on us as German and humanities scholars to engage multiply and critically, conceptually and materially with the nation-state.

Part of this needed engagement is a precise and sustained examination of the changing landscape. The increasing significance of supranational entities make German Studies more relevant than ever. Europe and the European Union have more influence on the global political stage than individual European nations. Germany is a key player in these larger entities as well as a unique force. Germans participate in subnational political groupings such as the euroskeptic, proto-fascist Alternative für Deutschland (AfD), but also in transnational entities such as the eurocritic, progressive DiEM25, a movement aiming to "repair" the European Union through stronger social provisions and more democracy, including a popularly elected constitutional assembly comprised of transnational European representatives. A range of scholarly perspectives are institutionalized in initiatives that research the multiple dialectics of Europe in / and Germany. For instance, the Freie Universität Berlin's long-standing Berlin Program for Advanced German and European Studies in 2019 published an anthology on Becoming TransGerman: Cultural Identity beyond Geography (Haakenson), the University of Pittsburgh recently created a PhD. program in Critical European Culture Studies, and a European Culture research network has been established under the auspices of Columbia University's Council for European Studies.

The examples above that highlight a few shifts in the meaning and force of Germany and Germanness and ways of making scholarly sense of them suggest another challenge: expertise. Teaching my "Film in the New Europe" course, I find myself thinking that it would benefit from the expertise of a team of colleagues working in different language-cultures in our now-long-amalgamatedand-downsized Languages, Literatures, and Cultures Department. Certainly, many topics are too large and too enmeshed for any single scholar to command. And, to take this case in point, a shift from transnational German Studies with a focus on Cuba to transnational European Film Studies would ideally involve not only collaboration but time to study several more national language-cultures and their film histories.

It may be unsurprising that even in mythically-social-welfare-oriented Canada, such a cadre of colleagues has long been ghosting; ranks are thinning even in well-endowed, private, and humanities-supporting US institutions. I am concerned that dispensing with the nation-state model would exacerbate this thin- 
ning. For one, national governments often support particular educational programs as a way of maintaining international ties. Furthermore, and with due respect to Jacques Derrida's philosophical insistence on our fundamental monolingualism and the welcome critique of identity politics that it encourages (see Derrida), language and culture are one cloth. (Critical) studies, whether European, German or (North) American or whatever must be able to work in multiple language-cultures to be rigorous.

We need the nation-state as a mode of analysis. Nation-states remain important global actors, materially and ideationally. They and their citizens have their sharp claws in each other, and their (transnational) collaborations may offer effective resistance to less democratic entities. A German Studies that reconsiders and reimagines the nation-state contributes to contemporary needs of our institutionally-based discipline, to scholarship, and to the broader society.

JENNIFER RUTH HOSEK

Queen's University

Between Nation-State and Transnational Openings: German Studies in Denmark German Studies departments in Denmark are characterized by a tension between the nation-state model as frame for the institutional educational setting, on the one hand, and transnational and cross-disciplinary developments of research on the other. This tension has to be seen against the backdrop of German-Danish relations as well as recent developments in the educational system in Denmark.

Throughout history, Denmark has had strong ties to Germany and German culture, which is partly due to its geographical position. At the same time, the Danish view of Germany was for many decades, or even centuries, rather distanced. Research on Danish national self-perception argues that the invention of a Danish national identity at the end of the eighteenth century largely emerged because of a desire to be distinct from the Germans. This conflict surfaced again during the civil war between German- and Danish-speaking parts of the country in 1848, but also had a strong impact on Danish self-perception after the war in 1864, when Denmark lost its German-speaking territories to Prussia. From this time on, Danish national self-perception often centered around the „Abgrenzung und wachsende Distanz zu Deutschen und Deutschland"(Langer 143).

For German Studies departments in Denmark (currently existing in Copenhagen, Odense, Aarhus, and Aalborg), this historical background poses some challenges. Germany and German culture are historically often perceived as the "Other," as the unknown and strange. In making sense of the cultural "Other," the model of the nation-state was the widespread frame that was used to explain Germany. To regard Germany and German culture as a "collective singular," as a 
coherent cultural entity, distinctive from Denmark and Danish culture, is one way to process Germany's otherness.

The history of German Studies in Denmark reflects these perceptions: Seen from a historical perspective, Danish German Studies often embodies the traditional notion of Fachgeschichte, which embraces a philological approach to literature, a traditional notion of Bildung, as well as a strong focus on grammar. Since German Studies attracts many students who would like to become German teachers at high schools, the curriculum often follows a classical design. The nation-state idea is in this context a common concept that streamlines the teaching of German literary history and literary works by reducing their complexity. Thus, until today, the institutional setting and the curriculum is often based on a traditional view of the field, which in turn uses the nation-state model as a frame to give German studies its justification to exist.

In recent years, however, we also observe openings and new perspectives within the discipline of German Studies in Denmark. First of all, during the last decades, the critical distance to Germany is dwindling. The construction of Danish national identity becomes more and more detached from the earlier distance to Germany and German culture. Since the beginning of the twenty-first century, we witness a new interest in Germany in Denmark and in the rest of Scandinavia (Florén and Höglund). This new attention to Germany goes hand in hand with the increased import of contemporary German films, music, and literature, and is often - even though it is still partly playing with the notion of exoticism-accompanied by a growing awareness of political, cultural, and societal developments in Germany. This change of perspective, which can also be seen as a reaction against geopolitical changes, xenophobia, and political discourses on immigration in Denmark (Schramm), facilitates (ironically) new transnational and interdisciplinary perspectives. The former gridlocked perception of Germany as cultural distinct entity in the public perception is slowly being replaced by a general understanding of a common European history, its transnational connections, and a shared entanglement in the political and cultural challenges of the future.

Secondly, the academic and educational system in Denmark opened up towards cross-disciplinary and transnational perspectives, partly challenging the historically grown idea of culturally stable entities described through the frame of the nation-state. These openings are partly due to recent neo-liberal trends in Danish academia. Education in Denmark is completely state-funded (all students get a salary independently from income, and there are no fees), and thus the Danish government is often quite in control of its procedures and content. This governmental oversight results (among other things) in the doctrine that the humanities should have an instrumental value to society and should contribute to the economic system of production. This is a vision that is often called "nyt humaniora" ("new humanities") by deans and heads of departments, and which is diametrically opposed to the classical Humboldtian Bildungsideal (Wucherpfennig). In relation to German studies, this development includes the 
risk of abolishing the specific philological profile of German studies as an individual and rather narrow academic entity.

As mentioned, it is precisely the neoliberal agenda in the university system which facilitated new cross-disciplinary and transnational perspectives in research: These utilitarian tendencies led for example at the University of Southern Denmark to the creation of mandatory research groups across historically grown disciplines and profiles. With the explicit aim to boost the possibilities for external funding, these research groups pull researchers from German Studies into different transnational and interdisciplinary settings. Both changes-the newly developing interest in German culture and the reframing of the humanities in the academic system-triggered a tension between the historical focus on the nation-state and transnational and cross-disciplinary openings. While national philology still remains predominant in the institutional profile of Danish German Studies, in particular in relation to teaching, the organizational setting of research is slowly, but decisively moving away from this kind of framing. These tensions have facilitated new cross-disciplinary research projects like "Art, Culture and Politics in the Postmigrant Condition" (led by Moritz Schramm) and "Drone Imaginaries and Communities" (led by Kathrin Maurer), involving researchers from various disciplines and affiliations in- and outside the humanities. In the area of teaching, new perspectives have emerged with seminars on transnational dimensions of German studies as well as courses on surveillance technology in popular culture.

At the same time, the top-down restructuring of humanities departments into cross-disciplinary and transnational hybrids cannot be seen as unambiguously progressive. Within the recent transformations of the academic system, ironically, the traditional Fachgeschichte (which in many ways embodies a more conservative approach, rooted in models of national philology), became a form of resistance against the recent neo-liberal trends in Danish academia mentioned above. Thus, while we accept the inspiring and to a certain degree necessary tendency to loosen the traditional and conservative profile of German Studies, there is also the danger of losing the traditional strengths of the humanities in the neoliberal setting of Danish academia, destroying not only the frames of the nation-state, but also the traditional elements of non-instrumental research. We have to defend the traditional values of German studies as Fachgeschichte and at the same time support the modernization of the curriculum without backtracking into neoliberal indifference and dissolution of traditional humanities.

There are no ready-made solutions on how to practice this balance. Making students aware of the limits and constructedess of national narratives about literature and culture, reflecting with colleagues on the curriculum and canon, as well as the courage to do non-instrumental and non-strategic research across the boundaries of national philologies are ways of dealing with these challenges. In relation to the structure of the German Studies education, this balancing act could be combined with more flexibility and openness, which at least potentially could 
allow combinations between Danish, German, and European elements-without losing the focus on German studies as an institutional frame. This way, one could even contribute to discussions about the national frame not only in German Studies, but also in the Danish academic system as a whole. When Germany as the cultural counter-point for the construction of Danishness is increasingly fading away, this opening could lead to a debate about the construction of Danish national culture as well.

Kathrin MaURer and Moritz Schramm

University of Southern Denmark

\section{Disciplinary History as Genealogy and Inheritance}

How can we tell the history of German studies? How should we? These questions provide a subtext for the present forum and for the article that partly inspires it, Jakob Norberg's "German Literary Studies and the Nation"(2018). In it Norberg links the institutionalization of Germanistik or German literary studies in the course of the nineteenth century to a strand of nationalism based in a dubious understanding of literature as a tool of nation-building and ethnocentric consolidation, drawing on this history to argue for the continued role the nation-state should play in contemporary German studies. I would like to tease out the historiographic assumptions that drive Norberg's genealogical account, which traces multifarious historical phenomena back to a shared beginning. While the story Norberg tells is not entirely unfamiliar, his account is helpful because it raises the question of our discipline's history while making an argument that is strategic and tactical rather than merely documentary. In other words, Norberg treats the history of our discipline as a legacy we construct and actively inherit, much in the way the question of modernism's legacy inspired the Expressionism debates of the 1930s (Schmidt, Die Expressionismusdebatte).

Norberg's approach reaps many rewards. Critical recollection of the discipline's imbrication in ethnocentric and nationalist thinking enables one to turn Germanistik's original sin into a most powerful weapon. As we inherit its legacy we can gouge out the one eye clouded by nationalist ideology in order to gain clarity of vision in the other, our self-critique hopefully earning us a privileged seat at the humanities' table. His narrative has the additional benefit of tying the development of the field to its institutionalization in national-language departments on two sides of the Atlantic. Finally, in warning about the perils of nationalism it connects our discipline to the resurgence of right-wing populisms and ethnonationalisms in our day, making a case for disciplinary relevance.

When told as a stand-alone story, however, the narrative also has significant limitations. In reinscribing the centrality of the nation-state for both German- 
language literature and German literary studies, it implicitly affirms a long-standing self-understanding of our discipline as the historical drama of hegemonic groups that skew white, male, heterosexual, and middle and upper class. In this drama individuals and groups that claim different affiliations and attachmentswomen, LGBTQ+ persons, persons of color, non-native speakers-have traditionally been cast in an auxiliary role as interlopers or newcomers who provide a useful corrective for a narrative whose main contours were set before they entered the scene. The story also tethers German Studies to the history of German-language Germanistik, sidelining disciplinary developments in other countries. It downplays the fact that German has been and continues to be spoken in a variety of national and supra-national contexts that don't easily fit with the history of the German nation.

I would like to embrace the active sense of disciplinary inheritance that powers Norberg's account while augmenting it through a different kind of genealogy, one that inverts its temporal vector by starting from the present as a moment of disciplinary self-questioning rather than the past as a place in which to look for the discipline's half-forgotten origin. The genealogical paradigm I have in mind treats the current institutional landscape as a mash up of disciplinary and epistemic sites that are shaped by different institutional, socio-political, and economic factors (see Foucault's Discipline and Punish for an example of this genealogical model). Depending on where one stands, one will discover multiple points of departure or turning points that call for acts of active inheritance. At Cornell one such moment was the establishment of the Institute for German Cultural Studies by Peter Hohendahl in 1992. This grew out of his and other colleagues' concern with connecting the study of literature and culture to its institutional roles, including nation-building, and was inspired by the work of first- and second-generation Frankfurt School theorists (see Hohendahl, Building a National Literature). This focus had led to expanding the German Department's philological and literary emphases to encompass scholarship on gender, the GDR, German-Jewish culture, film and visual media, postcolonial and transnational studies, and political and social theory. In short, at Cornell the concern with spelling out the relation between German-language literature and the German nation-state helped spur the wide-ranging interdisciplinary work that prompted the Institute's founding and continues to be central to its mission. Cornell's Department of German Studies has relied on this work over the years to forge strategic alliances within our university, nationally, and internationally. This has been pivotal to its continued existence as a self-standing department.

As I briefly sketch the historical partnership between the Department of German Studies and the Institute of German Cultural Studies at Cornell, I am acutely aware of the considerable resources vested in the Institute and our university more generally. This comes with the reminder that material resources and opportunities have been and continue to be distributed unevenly in the complex institutional landscapes we call German studies. For me this makes it all the more 
vital that we account for the multiple ways departments and programs actively lay claim to our discipline's legacy based on the situation on the ground. Their narratives will be affected by a host of disciplinary and material factors that weigh differently from case to case: whether German is in a self-standing department or not; how connected it is to other languages, departments, and disciplines; how its particular mission is shaped by the general mission and profile of the institution in which it is embedded (research university, liberal arts college, public or private university, etc.); whether the department has a graduate program; and the rigor of the language requirement at a given institution (if there is one).

Norberg's account places literary history at the core of our discipline, seeking to provide German studies with a rationale for the continued existence of selfstanding departments and programs at a time of institutional retrenchments and departmental consolidation. In my view the claim about literature's historical role can be a valuable tactical argument in specific institutional situations. I am however concerned that, in its abbreviated form, the argument fails to provide a substantive methodological rationale for engagement with the verbal arts. In other words, it is not grounded in an understanding of what literature is or how one best engages with its specificity as an object of knowledge in its own right. It also implicitly relegates other pursuits to methodological additions in the disciplinary expansion glossed as "German Studies." This potentially pits subfields against each other, forcing each into a defensive crouch while possibly giving historical arguments a self-interested and backward-looking slant.

I offer these observations not to find blind spots in Norberg's essay but to outline the additional intellectual labor his genealogical approach both enables and demands once one reads it as a practice of active inheritance. My point is that, much as for the other subfields that make up contemporary German studies, we should articulate the relevance of literature to our discipline in ways that are not merely documentary and historical. To be sure, since the linguistic turn the question of literature has been at the forefront of humanist and post-humanist endeavors, and there is no dearth of paradigms that make a case for scholarly engagement with the verbal arts. Witness, most recently, the debates around a New Formalism that upholds the distinctiveness of literary criticism while infusing formal analysis with historicist and materialist concerns (Levine; Kramnick and Nersessian). Such specialized discourses advance disciplinary inquiry but do not easily translate into formulas for program building and curricular reform. This raises the question of our own goals in making literature a pivot of curricular and research agendas. In my experience, the question "why literature?" often gives rise to a misunderstanding based in the fear that one misses literature's point and unique status when one discusses it too overtly in instrumental terms. While there is no cookie cutter-approach to the "why" question, I believe scholars and students should feel encouraged to ask to which uses, disciplinary or not, literature can be put. Otherwise one risks falling into stock narratives on responsible citizenship, cultivating the whole person, or providing a check to amoral science and corporate 
greed, which administrators employ when asked to quickly make a case for a department or a program. There is nothing wrong with these narratives if they are thought through historically and methodologically. If used reflexively, however, they unwittingly reduce the literary to valuable content packaged in historically resonant and rhetorically powerful language, making a claim for literature's ethical and institutional function that needs to be scrutinized and tested if it is not to become moralizing and normalizing.

I hope it is clear that I am not pleading for forgetting the national(ist) history at the heart of the canonical practices that for decades authorized German literary history. In my view this is one of several historical accounts we should be prepared to offer students and administrators when they ask "Why bother with German?" I realize that the inverted genealogical perspective I am advocating trades the neat genealogical funnel in which a multifarious present optically flows back to a point of origin for a jumble of tangled lines and multiple starts and turns. This may sacrifice the panoramic vision enabled by the origin narrative but delivers a fine-grained description of the diversity and vitality of our field today. The point is to develop historiographic practices that are comparative, transnational, and methodologically plural in order to lend voice to our field's multiple histories. PATRIZIA C. McBRide Cornell University

\section{Was heißt: sich entdeutschen?}

"Gut deutsch sein heißt sich entdeutschen." This sentence from Menschliches, Allzumenschliches (511) opens an aphorism in which Friedrich Nietzsche proposes that to be German is to become alienated from one's very status as German. The distinguishing feature of this people, if they are one, is the fact that they inexorably surmount their defining qualities. One is German not in virtue of having certain traits but because one excels at losing them, which means that one becomes German by forfeiting one's claim to being German before one possesses it. With identity and non-identity suspended between prospective and retrospective clashes of is, was, and will (not) be, the relationship between the individual and the collective- - .g., between a German person and the German nation-is murky at best. In this respect, Nietzsche's aphorism belongs to a well-established intellectual tradition in which conceptions of state power consistently involve apostrophes to an intrinsically indeterminate future. From Kant's attempt to write toward the (im)possibility of perpetual peace, to Fichte's address to a German people that does not yet exist, to the leap of faith Schlegel identifies as a crucial step toward republicanism, the German nation is less a distinct idea or stable empirical phenomenon than a self-divided dynamic that relentlessly interrogates the unifying 
principles around which a common canon, history, or language called "German" might be organized. German studies has thus always been, as Jakob Norberg recently called for it to become, "the meta-national discipline par excellence" (14), because it has always had to struggle with the difficulties of distinguishing between the German, the non-German, and the German-because-it-is-not-German.

One might object that what I have said to this point does not capture the specificity of Nietzsche's opening claim, since he writes not "Deutsch sein heißt..." but "Gut deutsch sein heißt...," implying that there may be a counter-formulation: "Schlecht deutsch sein heißt...." As complex as the relationship between "deutsch sein" and "sich entdeutschen" appears to be, "being German well" (or "thoroughly") may turn out to be no less obscure. The vagueness of the adverb gut raises the question of the nature of the evaluation that produces it. Are we envisioning being German "well" in an ethical, aesthetic, or political sense, or even as a judgment of ontological integrity? Alternatively, is Nietzsche saying something about the precarious relationship between being German and knowing the German language? In "gut deutsch sein," one hears an echo of "gut Deutsch können," suggesting that the neologistic "sich entdeutschen" names a distortion of language itself, as if the first step toward becoming German was learning to read, write, and speak die deutsche Sprache as an irreducibly foreign tongue. Moreover, as Nietzsche's faithful reader Martin Heidegger never tired of reminding us, the tantalizingly transitive yet intransitive verb heißen can articulate not just a simple statement of "this means that," but an active call for change (19-27, 157-59). Whatever else it says or does, a good German sentence demands a transformation of the German language, a rewriting of the rules and norms on the basis of which a given formulation would be deemed gut or schlecht.

Taking stock of these various complications, one might well conclude that Nietzsche's aphorism has little to tell us about the possibilities for German studies to thrive while productively affirming its connections with other traditions, languages, and disciplines, local or global. Teachers of German in North American colleges and universities are unlikely to be taken with the proposal that their language courses should offer instruction in a self-disfiguring German, and they may be similarly disinclined to embrace a call for a tradition that is forever in flight from its own self-identity, as if a German department were only worthy of its name once its field of study was no longer recognizably German.

Nietzsche was of a different mind. In a draft passage from Ecce Homo, he observes that his readership, like he himself, has a talent for self-transformation, declaring: "Wer mich heute in Deutschland liest, hat sich gründlich vorher, gleich mir selber, entdeutscht" (Kommentar 482). Even those of us who have never imagined that we were being German, much less being German well, may have begun to entdeutschen ourselves insofar as we read, or try to read, Nietzsche. At the same time, it would be wrong to assume that our common participation in some act of sich entdeutschen is the basis for a distinct, stable community of teachers and students of German studies. That the structure of the agency involved is considerably 
more precarious than this would suggest becomes clear when we consider that one of the most striking things about the sentence "Gut deutsch sein heißt sich entdeutschen" is that it contains no nouns. Verbs and adverbs do almost all of the work, as if Nietzsche were trying to craft a formulation that avoids the seductions of grammar by which the primacy of the subject-predicate construct underwrites the belief that every deed must be the act of a doer.

In order to translate Nietzsche's sentence into English, arguably an instance of entdeutschen in its own right, it is almost impossible to avoid introducing a substantive: "To be a good German means to degermanize oneself" (trans. Hollingdale, 287); "Being a good German means de-Germanizing oneself" (trans. Handwerk, 125). This may be an indication that German studies should concern itself less with the characteristics of German people or German polities and more with the characteristics of German events. It may also serve as a reminder that for all this talk of sich entdeutschen, one of the peculiarities-if not beauties-of the German language is the fact that without breaking any rules whatsoever, a sentence can be constructed by giving free rein to two infinitive verbs coordinated by the finite form of a third, with only the reflexive pronoun sich marking the subject/object of the activity described. Although he seems to be encouraging us to test the limits of "good" German, Nietzsche's prose is far from anarchic, just as, ironically, nothing could be more German than creating a neologism by affixing the prefix ent- to an adjectival noun that has been refashioned as a verb. In a slightly mocking fashion, Nietzsche hints that our claim to read, write, and speak Deutsch rests on our claim to read, write, and speak an Entdeutsch that does not yet exist. Perhaps, then, it is not so much that German studies needs the nationstate as that it finds itself in a perpetual state of uncertainty about whether it must first understand our allegiances to lexical and grammatical norms before it can contend with our allegiances to particular peoples or governments.

Jan MieszKowsKi

Reed College

\section{Outlandish Reading and the Critique of the Human}

My career as a student and then an instructor of German literature has unfolded outside the German speaking nations. As an Auslandsgermanist, an outlandish Germanist, an outlandish reader of German literature, I do not live the relationship of German writing to the nations that produced them. My outlandish position has always made me feel like I dwell outside the nation-state's claim on its cultural products. And I am quite at home with this. Not only does the nationstate provide a questionable model for understanding the nature of history, geography, culture, and politics; it is a dangerous ideology that in its very essence 
tends toward extremism. At worst, it spawns violent hate crimes; at its mildest it takes the form of what could be called a coercive or perhaps a pedagogical normalization of the human. In the wake of the Enlightenment, there is something about the pedagogical normalization of the human that has to arouse discontent. From Herder through Adorno and Horkheimer to Foucault, the terms of this discontent have been repeated —normalizations of the human align all too easily with the misuse of power.

The mistrust of the nation-state is part of the political unconscious of my generation of scholars. Deleuze and Guattari's vehement denunciation of the State and its inscription in the capitalized subject set the tone here. And yet, it is worth revisiting the terms of this mistrust. In the age of the multi-national or de-nationalized corporations, when labor internationalism seems to be completely off the table, the nation-state is starting to look like the best legislative building block of a possible democratic future. Furthermore, as Neil Smith observed, nationalization of financial institutions would be the best remedy for the disasters caused by financial globalization. Quite apart from legal and economic considerations, as an organizational concept the nation is deeply embedded in the institutions that promote my discipline. As a result, in the classroom culture walks a fine line between the affirmation of the nation-state as the cultural unconscious of the capitalized subject and its contestation in theory and practice.

To teach any literary work outside the nation of its production is to be caught between the idea of humanity as the common ground for understanding the literary work and the experience of lived cultural difference. The outlandish reader faces the task of accessing, understanding and appropriating an artifact whose conditions of production remain in many respects strange. This is true of any work taken as representative of a national literature; but it is particularly true of the literature of the German speaking nations. In the late eighteenth century, where my research is focused, there was no German nation-state. Even when I teach more recent literature, many of the works I teach were written in nations outside the (West) Germany that appears still to produce the normative institutionalized statements on German literature. And yet, even the canonical works of German literature resist pedagogical normalization under a national flag. They span not only the German speaking nations, but they include Romania (Herta Müller), Turkey (Emine Özdamar), and many more; and the further we move from the canon, the more untenable the nation-state template becomes.

If we pursue the process whereby German literature is realized in a local context outside Germany, it highlights the struggles within texts for an adequate concept of the human. The study of a national literature may enable a discourse of national specificity but it also enables a discourse of universality. An inquisitive reading outside the German speaking nations opens up the gap between these determinations, and in doing so it fosters a critique of the human. Because of how I started my teaching career, I am very aware of the tensions between pedagogical normalizations of the human and their contestation in the classroom. 
After studying in Johannesburg, I was hired as a junior lecturer in the Department of German Language and Literature at the University of Cape Town in January 1985. In October the previous year, Desmond Tutu was awarded the Nobel Peace Prize. A month before that, P.W. Botha had been named state president, enforcing the new constitution of 1983, which had been approved by whites-only referendum. The apartheid regime's new constitution was intended to counter growing resistance to this racist, white minority government. It granted the vote to persons classified Colored or Indian, electing representatives to their own racially segregated houses in a tri-cameral parliament, in which the White chamber had the power of veto. The effect was the opposite of what its designers had hoped for. There was a mass boycott of Parliament, and a new wave of mass protests shook the Townships. Botha deployed the South African Defense Force to quell the unrest, and the failure of this tactic led to repeated states of emergency beginning in June 1985. Foreign capital fled the country, the value of the currency plummeted, and the South African economy began to collapse.

Then, the first tentative moves to end the Cold War forced the negotiations for peace in South Africa. Behind the scenes negotiations with foreign capital fostered the peaceful transition to democracy, but at the same time they defused the radical political and economic agenda of the African National Congress, resulting in the neoliberal economic regime which has been struggling for legitimacy ever since. There is no better or more concise description of this than Sampie Terreblanche's 2012 book Lost in Transformation. As economic globalization changed the nature of the line drawn through the middle of the German nation-state, it changed the nature of the line drawn around racially categorized population groups in South Africa.

Outlandish reading harbors potential insights that are of crucial importance when it comes to the politics of the human today. The political and legal entity that is the nation-state finds itself increasingly questioned by institutionalized collectives that don't quite fit with their imaginary national correlates-a disconnect that is very familiar to outlandish German Studies. Once we consider the nation-state as a legislative entity in a multicultural, plural or policultural collective it becomes clear that it cannot simply be dismissed as oppressive. Drucilla Cornell has argued in Law and Revolution in South Africa (2014) that seeing the collective as policultural (Cornell adopts the term from John and Jean Comaroff) means refusing to accept that ethnic and other minorities are to be subjected to a common universal citizenship through violence and other forms of state-mandated coercion, and this in turn leads to the pursuit of a model of national legislation and jurisprudence that accommodates the policultural. To look at it this way means moving beyond a simple dismissal of the nation-state and of nationalist impulses in its citizens-even those whose colors wave toward the right. As a pedagogical normalization of the human, the idea of the nation-state also points toward an aspiration to universality which, ideally, itself points beyond the nation. It is within the dialectic of pedagogical normalization and its particularist rejec- 
tion in individual experience that universal ideals can be formulated—ideals such as universal suffrage, universal human rights and the like.

In my own research into the struggles over collective identities in the late eighteenth century, I have found that this policultural imperative has been a long time in the making, and that it has played a central role in the self-constitution of German cultural and political collectives. In his famous 1882 lecture on the nature of the nation, titled "Qu'est-ce qu'une nation?" Ernest Renan saw the fusion of diverse identities as constitutive of the German nation. But in today's secular multiculturalism, we see how unresolved the national fusion remains. Fantasies of cultural homogeneity face the reality of a plurality whose common ground is constantly contested in political and cultural terms. It was Herder's achievement to witness how the French Revolution was giving birth to the idea of a nationstate that insists on creating its own political constitution and determining its own political fate while at the same time working against the humanist ideals that drive its reformist and revolutionary tendencies. With this concept of $\mathrm{Hu}$ manität, which he spelled out in Lettters 27 to 29 of his Briefe zu Beförderung der Humanität (1794), Herder reminded his readers that the idea of the nationstate can only be subscribed to at the price of forgetting the heterogeneity out of which the idea of national unity arose. In this sense, Humanität can be regarded as an early statement of the policulturality of society-not just German society (in Herder's time) or South African society (in the twenty-first century), but society per se. Teaching and studying literature im Ausland pushes home the point that individual resistance to pedagogical normalization, whether this resistance is on the part of the instructor or the student or both, is the key to a literary critique of the human.

JOHN K. NOYES

University of Toronto / Stellenbosch University

\section{Which Model makes us more Adequate to the World?}

At the seventy-second session of the United Nations General Assembly (19 September 2017), Donald Trump emphasized his belief in the principle of national sovereignty: "Strong, sovereign nations let diverse countries with different values, different cultures, and different dreams not just coexist, but work side by side on the basis of mutual respect. Strong, sovereign nations let their people take ownership of the future and control their own destiny." In my Indiana University general education course, "Introduction to Radical Thinking," I juxtapose Trump's speech with The Communist Manifesto (1848). Is nation or class to be the vehicle by which our students control their destiny? One-hundred-and-seventy-one years after the Manifesto, class organization has yet to supersede the nation, but ar- 
guably what was once the incontestable primacy of the nation now stands in need of Trump's revalidation. Should today's precarious affirmation of the nation continue to serve as a model for Germanic Studies-and indeed for cultural studies generally-especially given the challenges posed by multinational corporations, supranational bodies, forced displacement, and global warming?

I want to take up this question in two ways. First, by recalling the medieval proposition veritas est adaequatio rei et intellectus [truth is the equation of things and intellect], ascribed to Isaac Israëli, which suggests that the truth of our discipline relies on it being structured adequately to the things of the world. Is that right, or are the insights we produce quite independent of the actual world of the moment, being instead creative constructions suited to the inexistent ends of the imagination? Second, assuming there is some structuring relationship between national language departments and the way the world is organized, what does such global organization suggest for interpreting ourselves to our publics? If we follow Jakob Norberg's persuasive argument in "German Literary Studies and the Nation," Germanistik at its founding moment not only corresponded to the world of nascent nationalism, but played a fundamental role in shaping it. As transformed as this national legacy has become, it arguably continues to secure a (shrinking) place for us in the academy.

An inquiry into adaequatio rei is part epistemological and part pragmatic. Cultural studies departments are not epistemologically constrained to produce objective truth so much as to pass along traditions, reconciling them with contemporary experience of cultural life. They help constitute what Hannah Arendt called "authority," in reference to the Roman distinction between potestas (political power) and auctoritas (respect for the inherited world). In Arendt's view, because humanity is constantly renewing itself across generations, our condition is fundamentally one of plurality (462-507). Each birth represents a novelty in human affairs, and as such a claim to renovate the world. But our condition is not only plurality and novelty, but also worldliness. As a historical (and mortal) species, we have crafted a realm that shelters and conserves what dispersed generations have achieved. Were we to fail to care for this created world, then each generation would, in blind assertion, stand only to cut down what came before. Authority, for Arendt, is stewardship of the world. It sustains the connectedness of our condition in the face of its novelty and plurality. Arendt's characterization comes pretty close to how I see at least one aspect of my job in a cultural studies department. In this respect, we are not leading but lagging indicators of social change, we are not disruptors and purveyors of shock, but mediators and kindlers of epiphany. We may be one of the last refuges of the nation.

At the same time, our authority is very partial, to say the least, tasked with one small corner of cultural mediation and personal inspiration. The form of the world whose shelter we tend remains recognizably national—associated with proper names like Germany, the Netherlands, Austria - however much we have complicated those names by reflection. But the site where we express the Germanic 
world is the university, and, indeed, for many of us, universities outside Germanspeaking regions. The shrinking corner of our authority on the US campus is where the reality principle cuts across our cultural aspirations. The costs of our inadaequatio with respect to present trends are not abstract and epistemological, but concrete and ontological. If we don't reflect in our structures and practices the reality of what our communities perceive as relevant to their life experience, our ideals become wan and detached, dogmatic or decadent. To be sure, the segment of the world to which our structures need to be adequate is filled not by the contest between the nation-state and its successor forms, but by the university system, which accommodates itself to the larger forces arranging political, economic, and cultural capital in the world. Doubtless, then, we bear some attenuated burden of adequation, commensurate with our rather peripheral position, to the way sovereignty and globalization affect the significance of the material we call German. But because cultural capital is a lagging indicator in comparison to political and economic capitals, we don't signal new trends so much as disclose their effects in shared forms of life.

Let me contribute my bit to bearing the burden of adequatio. What does Trump's UN address signal about the nation-state model and its prospects for continuing to frame our practice of cultural studies for upcoming generations? Trump's fights with allies in NATO and the EU, his abandonment of NAFTA, TTIP, and TPP, as well as his trigger-happy trade war policies, are often taken to indicate US abandonment of the multilateral structures put in place after World War Two. One way to interpret the debate over Trump is to ask whether such withdrawal into national sovereignty represents weakness in the form of the U.S. abdicating its global leadership, or consolidation of national power to meet rivals on better terms. A debate between the economic historian Adam Tooze and the sociologist Wolfgang Streeck gives us a better way to frame the issues, one that brings the dominant role of capital back into the picture. In his epic account of the 2008 financial crisis, Crashed (2018), Tooze argues for the international dimensions of both the crisis and its resolution. Not sovereign debt and national trade imbalances, but interbank lending caused the crisis, and new global structures of liquidity provision were its answer. In order to address such changing expressions of capitalist regulation, policy (and presumably also politics) must, according to Tooze, be supranational. Streeck, by contrast, is skeptical of capital's prospects of inventing its way out of the crisis, arguing that it has bought time by shunting its growing burdens of debt back and forth between private and sovereign borrowers, but its liquidity problems aren't being solved by these maneuvers, and its repertoire is fast coming to a disorganized end. Because no proletariat is in sight to ascend the historical stage and pick up capitalism's pieces, Streeck believes we have to risk a populism based in experiences of shared life (social cohesion, solidarity, governability) and return to coalition-building on the national terrain. Streeck is not celebrating nationalism as our destiny like Trump, but sees the nation as the only ground where a meaningful class politics can be pursued 
as in Marx. For Tooze, however, national democracy is too crude a tool to reshape the intricate and pervasive device that global capitalism has become.

This is not the place to settle the debate; rather, what the disagreements show is that the question of the nation-state is not easily dispensed with by reference to cosmopolitan moral goods (Willkommenskultur) or technocratic realism, which follows a logic largely unfriendly to the humanities, whose focus is forms of life rooted in "culture." From where I stand, I'd argue against abandoning the national roots of our position in the university structure if doing so meant surrendering our imaginations to the placeless logic of enrollment maximization and career success. Yes, "erst kommt das Fressen," and our students' stomachs are also our concern. But I imagine many of us have had at one time or another the feeling that it would be better to fold up shop with dignity intact than, in a spirit of "vorauseilenden Gehorsam," to adapt to a world in which citizenship means being an early adopter of the next technical fix. In political economic terms we are a lagging indicator, but as long as we retain some cultural authority, we have a prophetic role to play.

BENJAMIN ROBINSON

Indiana University, Bloomington

\section{Respectful Relations and the National Paradigm}

I am writing this forum piece from Treaty 6 territory, a traditional gathering place for diverse Indigenous peoples including the Cree, Blackfoot, Metis, Nakota Sioux, Iroquois, Dene, Ojibway/Saulteaux/Anishinaabe, Inuit, and many others whose histories, languages, and cultures continue to influence the vibrant com-

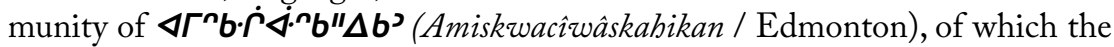
University of Alberta, my institutional home, is a part. I am also writing from multiple subject positions: chair of a large modern languages and cultural studies department, researcher of digital feminist German Studies, and settler scholar in what is currently called Canada. It is the intertwining of these subject positions that guide me in the considerations here. The territorial acknowledgment pays respect to and names the land's original inhabitants. It also points toward the historical dispossession of its residents by settlers while reminding of the violence enacted by colonial systems that lives on in the present. This includes also the academy, where the legacies of imperialism persist in structuring its mechanisms and Indigenous peoples continue to experience erasure in many disciplines. Since the Truth and Reconciliation Commission final report's 94 "Calls to Action" in 2015, universities across Canada have sought out ways to forge respectful relations with first peoples through efforts to indigenize the academy. In the Faculty of Arts at the University of Alberta, this has included recruiting Indigenous faculty 
members to departments with little or no representation, encouraging the development of Indigenous course content in all disciplines, offering workshops on topics such as Indigenous pedagogy or feminisms, welcoming elders into meeting spaces, and developing Indigenous student supports, among other initiatives.

The process of indigenizing the academy forms a backdrop against which any conversation on the future of German Cultural Studies as it is taught and researched in Canada, and indeed North America, must take place; such a conversation goes hand-in-hand with a recognition that the success of the nation-state model relies on the history of the land on which our work takes place. In his 2018 article entitled "German Literary Studies and the Nation," Jakob Norberg writes of the importance that nation played in the shaping of German Studies since the early nineteenth century. "German literary studies, or Germanistik, was a form of nationalism in itself; it articulated, supported, and sought to substantiate nationalist ideas"(1). German Studies departments, programs, and professional organizations in North America continue to be shaped by the "supposedly distinctive national culture" of German-speaking countries (1). Even new methodologies, theories, and medias or alternative texts to the canon do not unsettle the fact that the national paradigm remains the central organizing principle (12). Much of this narrative is also about who is not encompassed by the national moniker. "The discipline maintains itself by its continual application of - and critical reflection on-the distinction of German versus non-German"(12). The impact of such delineations based on "German versus non-German" could be formulated poignantly thus: "[I]f white Germans have long viewed the nation as a white one, then race would never figure an important role and non-white authors would be viewed as deviations from a white norm" (Layne 224). The study of German culture has long shut out non-white populations in its curricula, structures, and objects of research; this exclusion stems from the nationalism at the heart of the discipline.

To date, Indigenous learners, scholars, and community members have rarely been accounted for in conversations on the structural inequity inherent to German Studies, lumped instead into the greater pool of underrepresented populations, this despite the manner in which those bodies promoting its study in North America utilize German-language immigration as key to promoting language interests. The story of German-language settler colonialism has been written without mention of the violence done to Indigenous peoples in the process. Recognizing and owning this erasure is key to rethinking the discipline. If we are honestly to ask whether the nation-state model should continue to shape our discipline, we must consider first the role that German, and thus German Studies, played and continues to play in the Western project of settler colonialism, and where German Cultural Studies fits into, and potentially productively complicates, that picture.

One approach might be to do away with conceptions of nation and national belonging in German Cultural Studies altogether. Would this solve the perpetuation of violence and exclusion that are the legacies of the hegemonic political 
form of the nation? Cultural Studies writ large is interdisciplinary, transnational, and comparative; its objects are at once global and local. Doing away with national allegiances in the study of culture in our discipline would therefore be quite simple, resulting in potentially exciting connections among objects of inquiry across times and places, producing research questions that would allow for the probing of solutions to contemporary problems all nations share. Indeed, such a nationally-unhinged approach applies well to monolithic multilingual language and culture departments such as my own. In my administrative work, I have been part of a five-year collaborative process of restructuring graduate and undergraduate programs in languages and cultures away from national belonging and toward cohorts based in and across disciplinary expertise. In our collaborative article, the members of the departmental leadership spearheading these changes write of the new programs' focus on how shared investments in critical cultural analysis, media theories, or social justice movements take primacy over allegiances based in nationhood and linguistic identity, offering productive, transdisciplinary, and transcultural interchanges among students and faculty (see Beard et al. for an expansive discussion of these changes). This shift also allows for concerted and organic incorporation of local and international community service-learning and self-directed professional development units.

But even in this new departmental structure, formulations of nationhood and conceptions of national belonging do still feature strongly; they are not, nor should they be, entirely done away with. Therefore, scrapping the nation-state from German Cultural Studies as a discipline may not be the simple answer. By doing away with nation as the organizing principle for the study of German culture, folding that study into other disciplines such as anthropology, English, or history, we would forgo critical analysis of the impact that German-language nationalism has made both within geopolitical borders of Austria, Germany, or Switzerland as well as in the project of settler colonialism extending beyond these borders. This analysis is particularly salient for those of us who have long been deeply invested in feminist principles of social justice in teaching, research, and leadership, for these principles would demand that German Cultural Studies take local struggles (whether local means community or institutionally specific concerns) into account; this must also include an understanding that decolonization is an essential, and different, struggle. In their highly influential essay "Decolonization is not a Metaphor," Eve Tuck and K. Wayne Yang warn that "decolonization specifically requires the repatriation of Indigenous land and life" (21). It can, therefore, not be used as shorthand for social-justice movements nor as a catch-all term for efforts to diversify the academy. An evaluation of the nationstate in the project of German Cultural Studies means engaging in important and uncomfortable conversations around how race and whiteness are written in (or out) of its curricular and research objects. However, given the Canadian institutional commitment to building respectful relations through indigenization, this also includes a distinct discipline-wide conversation on how to truly decol- 
onize German Cultural Studies-instead of de-nationalizing it-in a way that would include restoration of Indigenous world views, cultural practices, and relationships to the land in meaningful ways. In Building Transdisciplinary Relationships: Indigenous \& German Studies (Watchman, Smith, and Stock), contributors from both disciplines explore some of the possibilities that are opened up when such a conversation begins in earnest.

It is difficult to hold two competing truths simultaneously. German is under constant threat across North America, with language enrolments declining, programs closing, and reliance on precarious labour on the rise; German is also built on an aggressive settler colonialism fuelled by nationalism that is the heart of the discipline. But might the tension between these two truths actually lead us toward an orientation of German Cultural Studies that looks not toward the nation-state as an organizing principle, nor away in favour of a denationalized view, but instead looks askance at its histories, structures, and legacies? By shifting the orientation to the nation-state, and therefore also the orientation to nationalism, out of the center, space is made for the inclusion of, among other things, Indigenous practices and principles. Such a shift would necessitate a reframing of learning outcomes as well as a rethinking of expectations around what constitutes disciplinary objects of research, research questions, methodologies, and modes of output. Further, professional bodies and institutional leaders would need to advocate for different modes of assessment for hiring and tenure and promotion committees as well as forging collaborations with Indigenous scholars and community leaders. Such a broad-based rethinking may become a model for the future of other nationallyaligned cultural studies programs in the European (settler-colonial) languages.

CARRIE SMITH

University of Alberta

\section{The Lost Middle}

Thirty years ago, as the events surrounding the opening of the Berlin Wall were unfolding, I was living in Berlin on a dissertation research grant from the DAAD. The grant had been awarded to support my research on a cultural history of the German-speaking Prague writers of Franz Kafka's generation (later to be the basis of Prague Territories). My main archives were behind the so-called Iron Curtain, in the Czechoslovak Socialist Republic, in a city that had never been part of Germany. Nonetheless, the DAAD - the cultural arm of the Federal Republic of Germany - was my best shot at finding a research sponsor for this project. Relevant archives outside of the ČSSR were in Israel, the United States, and West Germany, particularly the Deutsches Literaturarchiv Marbach, which saw and sees itself as the proper and logical repository of the literary remains of Prague Jews who wrote 
in German. All this points to the fact that something other than the "nation-state model" has governed German Studies and the institutions that support it, even in the period before recent transnational and other challenges to it.

By the time I was back in the United States two years later, people were beginning to talk a lot, again, about "Central Europe," a pre- and now post-Cold-War region that had been transected by the pre-1989 German-German border along with that between Austria and Czechoslovakia, Hungary, and Slovenia. In modern language and literature departments and divisions, we began to speculate that Russian-dominated Slavic Studies and German Studies both might have to give up space for a Central European Studies that responded to the new reality as well as a historical one long repressed under Communism. Milan Kundera, Timothy Garton Ash, and others had done much to put this lost region back onto our mental maps in widely-read if controversial essays leading up to 1989. Whereas graduate students in German history may have learned French as their second foreign language in earlier generations, students my age learned Czech or Polish; we imagined a new cohort of graduate students in our programs along with students in Slavic Languages and Literatures that would specialize in Central European History, rather than configurations of fields and subfields that corresponded to modern nation-states and the boundaries of Cold-War alliances. That assumption proved partially correct in the short-term and fatally misguided in the longer term. A small cohort of scholars in this field did emerge, but a reconfiguration of language and literature departments or even the subfields within them did not follow, and the job market came to follow suit. Czech and Bosnian/Croatian/Serbian (BCS) did grow in Slavic Studies departments, but students wishing to couple these with German, Hungarian, or Romanian language were wisely dissuaded from it and usually encouraged to develop competence in Russian instead. German departments rarely produced student projects crossing the boundaries to Poland, Hungary, the Czech Republic, Slovakia, Slovenia, and so on. The promise of a recovered Central Europe in scholarship was hence relegated to Comparative Literature, and job placement proved to be more than challenging for those students daring to pursue these interests in that specific disciplinary context.

I identify chiefly as a cultural and intellectual historian of Central European cities, and the subfields I have contributed to most frequently have included secular Jewish studies, the cultural history of the Habsburg empire, and the history of sexuality. Each of these regions of study, albeit in different ways, has seen itself as transnational by some definition or other for virtually the entire time it has existed. Nonetheless, the transnational turn of the past decade or two has altered the way in which these fields conceive themselves beyond nation-states, or in inter-cultural terms. A generation of innovative young scholars in Central European Jewish studies (including Maya Barzilai, Marc Caplan, Shachar Pinsker, Naama Rokem, Rachel Seelig, among others) has defined itself in terms of a vector of converging linguistic cultures: German, Yiddish, and Hebrew, and sometimes also including Slavic languages. In German literary studies as such, even German-Jewish literary 
studies, such a conception would need to be different, but related moves can clearly be seen in studies of Turkish-German and other minor literature studies (Gizem Arslan, my colleague Kristin Dickinson, and former colleague Kader Konuk, for example), as well as new interpretations of the high German canon. Intercultural studies of Franz Kafka-the subject of Kafka im interkulturellen Kontext (Höhne/Weinberg), but also of several other Kafka projects-have by now required of their scholars a command of Czech, Hebrew, or Yiddish. David Suchoff's study of Kafka's "Jewish languages" offers a more satisfying account of the debt owed to a multi-linguistic context by the premier German-language modernist's work than we had before. The volume on interculturality mentioned above and ongoing work by Marek Nekula and others introduce new ways of seeing the importance of Czech in understanding the same work.

Kafka studies may be key to the question raised by this forum in a number of ways, and I expect other contributors will have discussed this from various angles. One could argue that the cornerstone work by French theorists Deleuze and Guattari introducing the long influential notion of "minor literature" set in motion a reconfiguration of language and literature studies that may still be detected in some of the radically new interpretations of German and Jewish literature that I have already mentioned. Of course, the very idea of identifying Kafka with a nation-state of which he was never a citizen and only briefly even a resident raises obvious questions. In Kafka's case this clearly goes beyond the degree to which the same may be true not only of other Habsburg Austrian authors and Germanlanguage writers from much further afield. That is due perhaps to the palpable contribution his high modernist prose made to German literary language itself. The tensions of "German Studies beyond the nation-state model" that this forum aims to bring out have very recently been dramatically acted out through the court dispute over the proper archival home of Max Brod's literary remains. As I have discussed in a recent book chapter, while the court case itself was adjudicated on the basis of Israeli family and inheritance law, the discussions surrounding it were necessarily saturated with essentialist questions of national homeland and patrimony, in ways that brushed right against the grain of Kafka's own life and work (see Modernism without Jews?). That so much seemed to be at stake in these questions both for the Deutsches Literaturarchiv Marbach and the National Library of Israel in Jerusalem highlights the continuing entanglement of the investment in national cultures and state institutions (the "nation-state model") pertaining to the commitment to cultural legacy.

In my current work on cities of the former Habsburg empire and in other contributions of the past years, I have turned my attention to Jewish German-language writers from Eastern Europe, particularly Galicia and Bukovina on the Eastern frontier of the Danube Monarchy. Much of the previous work on the choice of German as a language of literary and scholarly expression by this group, it seemed to me, leaned toward suggesting that the German lingua franca offered a kind of grounding for a population that was, in Deleuze and Guattari's terms, 
deterritorialized in their own homeland. I have always found that actually reading the literary production of Joseph Roth, for example, but also of so many other lesser-known writers, sooner displays a sense of instability, unsettledness, deterritorialization, rather than the reterritorialization that people projected unto them. That is perhaps the very characteristic that has allowed them to do something new within German (consider, as a striking example, the work of Paul Celan). Rose Ausländer and a whole group of other poets from Czernowitz offer different and therefore differently illustrative cases. What these examples and others show is not just that the study of so much of modern German literature must be explored outside of the frame of the nation-state model, but even, and importantly, outside of a conceptual framework of German-language culture. They require an imaginary that reconstitutes the lost middle, not a middle-ground of friendly or cooperative or diplomatic cultural mediation, but one that emerges out of the opposite of these-out of a maelstrom of conflict and alienation and resistance that nonetheless yielded to influence, appropriation, adoption, and love.

It would seem, then, less necessary to call for a de-nationalization of scholarship than to consider the difficulty of accommodating the proliferation of transnational, transcultural, and intercultural work on German-language culture within certain stubbornly national institutional frames. Among those I have mentioned, some (funding agencies, archives, and so on) cannot easily but also do not need to be altered in any way for this work to be pursued and appreciated. The demonstrated lack of flexibility of our own academic structures is in this sense both a larger concern and a more surprising impediment.

SCOTT SPECTOR

University of Michigan

\section{German Cultural Studies in Australia: Beyond Nation and Department}

As Australian scholars working at the margins of more canonical visions of German studies - one of us a scholar of literature, theater and film with a focus on migration, flight, and displacement; the other a cultural historian of gender and sexualityand at a significant geographical remove from relevant archives and conferences, we are frequently reminded of the need both to question, and to find creative and evolving ways of defending the ongoing significance of German cultural studies in the twenty-first century. Our teaching, too, is no longer embedded in "departments" of German, but more often within larger, cross-disciplinary entities that often include scholars working in literary and cultural studies and linguistics across the major European languages, as well as in fields such as gender and film studies.

The Australian Research Council, Australia's central funding body, has strongly favored interdisciplinary research in recent years, and thus universities have a clear 
interest in fostering research that looks beyond traditional disciplinary classifications. Recent successful German and European studies projects, for example, focus on the transnational emergence and circulation of ideas with broad intellectual, scientific, and social implications, including the cultural history of the case study genre across literature, medicine, and psychoanalysis, or the historical emergence and shifts of ideas of the "normal." Others have appealed to the widespread public fascination - even on the other side of the globe - with entities such as the East German Stasi, or taken a new perspective on transnational colonialist histories, such as German involvement in the nineteenth-century Boxer Rebellion in China.

Our own research frequently pushes against the limits of nation-based models. In the field of German-language literature, postmigrant writing has been prolific for more than two decades now, leading first Leslie Adelson to observe a "Turkish turn" and then Brigid Haines to diagnose a complementary "Eastern turn." Haines argues that the writing of authors of the "Eastern turn," such as Saša Stanišić, Terézia Mora, Ilija Trojanow, and Olga Grjasnowa, "resists containment within historical, national, and linguistic categories" (146). Indeed, Mora's laconic statement "Ich bin genauso deutsch wie Kafka" $(26,28)$ reminds us that much that is central to German writing and culture originated beyond the borders of the modern German nation-state. Haines thus suggests that it may be time to "retreat from national or linguistic identification and the concept of distinct cultures inherent in the term 'interkulturelle Germanistik,' and to talk instead of the transnational and porous nature of writing" (147).

Despite the inroads made into German-language literature by some postmigrant writers, Fatima E1-Tayeb convincingly argues in Undeutsch that certain groups of postmigrants (Roma, Sinti, Muslims, etc.) are still constructed as "Ungerman" and excluded from the national narrative. On German stages too, there is currently little reflection of the reality of a pluralist society in either the narratives staged or the actors performing them. The artistic director of the Gorki Theater in Berlin, Shermin Langhoff, who often points to the central role of theater in the way the German nation was initially imagined in the late nineteenth century, is a prominent exception, and consistently tries to ensure that the national narrative is expanded to include postmigrants through her theater programming and biennial Herbstsalon visual and performing arts festival (Cornish).

Doing the history of gender and sexuality, too, frequently necessitates looking beyond the contemporary limits of "Germany." Interrogating the rise of the boyish "New Woman" in the early twentieth century, for example, involves looking both at the specific popular and subcultural meanings that accrued around this figure against the background of Weimar Republic democracy and the expansion of citizenship during these years, but also its transnational implications in the wake of global conflict and shifting gender role expectations both within and well beyond Europe. Equally, recent efforts to interrogate the "German origins" of many of our contemporary sexual categories—such as historical ideas of the "invert," "homosexual" or "transvestite" that have formed the basis of today's queer and trans iden- 
tities—-demand that we deploy a decidedly broad definition of "German" that extends well beyond that country's current geographical borders. Scholars such as Kirsten Leng, Scott Spector, and Robert Tobin productively emphasize the broad transnational linguistic and cultural affiliations of "German" intellectual and scientific discussions of the nineteenth and twentieth centuries, proposing clunky yet fitting designations such as "German-speaking Central Europe" to describe these border-crossing conversations, while emphasizing that they extended to "ethnically" German populations in Italy, Hungary, and Russia, to countries of emigration such as the United States, and to colonial contexts such as the South Pacific and Southwest Africa. More broadly, historians have long been advocating that we "Europeanize" German history across these crucial periods of empire and nationstate building. While this push was particularly strong, as Ute Frevert observes, among intellectual and cultural elites before World War One, "both identifications [that is, German and European] could and did coexist side by side throughout the twentieth century" (88). They have also clearly persisted into the twenty-first, particularly when one considers continental responses to Brexit, or the re-enactment of inner-European borders in response to the perceived refugee "crisis."

The ways in which nation-state models shape our teaching have also changed significantly in recent years. In Australia, too, German Studies was traditionally institutionally reliant on the model of the linguistically and culturally defined nation, as Jakob Norberg observes of the United States. However, over the last twenty-odd years there has been a tendency for German Studies departments to be folded into schools or departments with other modern language disciplines, or sometimes to be combined with linguistics, English, cultural studies, gender studies, and even classics. This has created opportunities for much greater interaction between scholars working across different language and culture disciplines, and increasingly classes have been developed that examine German literature, film, and history alongside the literatures, films and histories of other cultures. Taught under labels such as "European studies" or "European critical theory," often with separate, language-specific tutorials, these shifts have proved a productive means of increasing student numbers in areas of research-led teaching, complementing the more specialized upper-level courses in German cultural and literary studies that represent the traditional mainstay of university language programs. These offerings sit alongside the growing ab initio language teaching that our programs provide, and on which much of our revenue depends.

In the Australian foreign language classroom, though, German is often primarily associated with Germany, and even Austria and Switzerland are often mere footnotes in some of the most frequently utilized language textbooks (which tend to come from either Germany or the United States). Yet we, and many of our colleagues, endeavor to creatively complement such material in ways that push students to question the inevitability of current national boundaries and ideas of "German" identity or Heimat, and to explore intersections between these and other factors shaping our experiences of the world. 
Teaching Antje Ràvic Strubel's novel Unter Schnee (2001), for example, about an East-West queer female couple holidaying in the early post-Wende years in a Czech ski resort, offers opportunities to integrate feminist and queer theories of intersectionality, performativity, and affect, while encouraging students to imagine what it might feel like to have grown up in a nation-state that no longer exists. Using literature, we can begin to push back against dominant understandings of national or even regional citizenship and belonging, while also using such texts to interrogate heteronormative expectations of binary gender and sexuality, and inhibitive ideas of race or ability. Another means of decentering the nation-state in the classroom can be through a focus on specific cities, sites, or genres. A course focusing on "Berlin stories," for example, could examine Walter Benjamin's nostalgic memories of the imperial European city of his pre-exile youth; the global significance of the German metropolis as a hotbed of modernity during the Weimar Republic (with the capacity to integrate exciting new productions such as Babylon Berlin); the experiences of living in the shadow of the Berlin Wall; or the ways in which, more recently, ideas of national and urban belonging have been decentered and renegotiated through the perspectives of refugees and displaced peoples in works such as the documentary film Neukölln, Unlimited (2010) or Jenny Erpenbeck's novel Gehen, ging, gegangen (2015).

From our Australian perspective, German Studies has already begun to show how it can not only survive, but also thrive as a result of the rich cross-disciplinary exchanges enabled by being located in structures other than classic "German departments." Funding structures increasingly reward work that looks beyond the boundaries of the nation-state, and this puts a growing onus on scholars to convey the relevance of that research to the taxpaying community-this includes specific justifications of the "national benefit" of topics emerging from German cultural studies to the wider Australian community. German Studies, we believe, has the capacity to meet the challenges it currently faces, particularly when it manages to connect with students' own plural and intersecting experiences of identity and place, through teaching that reflects the multiplicity and richness of the Germanspeaking world in both the past and the present.

BRANGWEN STONE and KaTIE SutTon

The University of Sydney, and Australian National University, Canberra

\section{Local, National, or Planetary Scale in the Anthropocene}

Scale plays a significant role in the environmental humanities, and studies abound comparing the most effective level for activism and knowledge (local, regional or global/planetary) in the face of climate change and the current mass extinction event- the sixth in our planet's history. Traditional approaches in the field look to 
the local as an accessible and human-attuned level, while others such as Ursula Heise's Sense of Place and Sense of Planet emphasize shared responsibility across continents and an international "eco-cosmopolitanism" that expands this view to the global, or rather, "planetary" level. The discussions in the environmental humanities rarely turn to the "nation" as the frame since ecological systems exceed national and political borders; indeed, mountains, oceans, rivers, wind, plant and animal life, and weather have their own flows and forms that pre-date much of human culture, or at least the modern nation-state versions thereof. Furthermore, the anthropogenic (humanly caused) alterations to these ecological systems such as pollution, radiation, development, deforestation, desertification, extractive practices like mountain-top mining and fracking, and industrialized agriculture (to mention just a few) do not stop conveniently at the humanly-drawn lines around a single nation. Climate change and its ilk therefore require a larger, even planetary, scale - even if that problematically projects an artificially global or even universal "human" impact abstracted away from actual, and widely differing, economic and cultural practices.

The problem of scale in terms of "nation" is further exacerbated in the environmental humanities by two other significant issues. The first reason is, of course, that most academic scholars in the humanities work in departments built around "national" or language-based foci; hence our work inevitably leans towards one language tradition or a nation-state-based emphasis even if no nationalism is intended. Secondly, nations make laws that have very concrete environmental impacts. While the ecological flows are not delimited by nations, the legal and thus practical responses to environmental issues are still primarily nation-based.Indeed, it is at the national level that decisions are made as to whether, say, climate change deserves attention, or what amount of chemicals is acceptable in drinking water. Since we are all imbricated into local ecological systems that exist within, and are impacted by, state, national, and international laws, the environmental humanities (and sciences) must grapple with all levels of scale. Avoiding the nation-level scale ignores the laws that shape practices and, especially relevant for the environmental bumanities, it overlooks the (often troubling) national and cultural ideologies that shape our sense of the "human" relationship to "nature."

Further adding to the complexities of scale for the environmental humanities, we are now officially in the planetary age of the Anthropocene when human beings count as a geological-level force. The Subcommission on Quaternary Stratigraphy's working group on the "Anthropocene," led by Jan Zalasiewicz, has officially voted in April 2019 "yes" to the question of whether the Anthropocene should be treated as a formal "chrono-stratigraphic unit" (since one can trace measurable amounts of industrial particulates from anthropogenic activity in the soil across the entire planet). We are no longer in the geological age of the Holocene but rather the Anthropocene. Already long before this vote by the Subcommission, the number of publications across all fields using the Anthropocene as a frame or in the title increased dramatically. Debates continue regarding both the implications of this designation and when it began: with the (early) advent of agriculture, 
the industrial revolution and the steam engine (and the concomitant increase in colonialization and slave plantations), or with the 1940s testing of nuclear bombs that left measurable traces of radioactivity across the entire planet. Regardless, since the activity, ideologies, and material processes of human culture have brought about the Anthropocene, it necessarily requires analysis by the bumanities and not only the sciences. And locating the nation in this mess is a tricky business.

In terms of the meaning of the Anthropocene and the cultural responses, Gabriele Dürbeck's exemplary work to define the era for German studies describes typical Anthropocene-narratives across all fields. Bringing together more than sixhundred publications from the humanities and the social and natural sciences since the year 2000, Dürbeck discerns an inevitably "planetarische Perspektive auf die globale Umweltkrise" (4). Her work on narrative forms provides a concrete system for addressing the abstract aspects of "planetary-level" perspectives. With such cross-cultural work, we might create much-needed bridges across the national/language boundaries in the humanities, particularly since most ecocritical texts without a national or language tradition in the title are still just English-language studies focusing on Anglophone texts. On a positive note, the field has been experiencing a huge upsurge of publications from all over the world (planet) resulting in a necessary expansion beyond English with numerous new books and studies concentrated on "other" traditions, though these mostly also focus on one nation or region such as Australia, Canada, China, Greece, France, Germany (my own co-edited volume with Caroline Schaumann, German Ecocriticism in the Anthropocene), Iceland, India, Italy, Latin America, Norway, Taiwan, and Turkey. Few of these explore the implications of their seemingly "national" emphasis; some offer initial steps with comparative analyses such as the Scandinavian examples and Ursula Heise's preface to our volume explaining the differing North American and German / European approaches to environmental humanities.

Heise's concept of eco-cosmopolitanism offers a promisingly comparative approach to environmental humanities in the wake of so much unacknowledged Herderian-like concentrations on regional and national characteristics. She criticizes the idea that the local is "natural," "while allegiances to larger entities-modern society, the nation-state - have to be created by complex and artificial means. But as analyses of nation-based forms of identity have shown, individuals in certain cultural contexts readily identify themselves as belonging to very large-scale and abstract entities of which they have only partial personal experience" (61). She notes that our ecologically-relevant activities in the twentieth and twenty-first century are, for the most part, shaped by globally interconnected processes and exchanges. Since one cannot simply claim the local as the primary place that defines us, Heise suggests that we need a "sense of planet": "In a context of rapidly increasing connections around the globe, what is crucial for ecological awareness and environmental is arguably not so much a sense of place as a sense of planet-a sense of how political, economic, technological, social, cultural, and ecological networks shape daily routines" (55). The challenge is to keep the planetary views accessible. 
Moreover, the nation-state necessarily remains a concrete influence on environmental thinking, regardless of how porous our borders are when thinking ecologically or about human cultural and linguistic movements. After all, "global" views have a troubling association with economic "globalization," and national laws shape most environmental practices. Reinhard Hennig provides an excellent model for an ecocritical study of "nation" in environmentally-oriented texts, nature myths, and politics in Umwelt-engagierte Literatur aus Island und Norwegen. Ein interdisziplinärer Beitrag zu den environmental humanities. In this comparison of Iceland and Norway, unusual for its insistence on thinking specifically about national differences, Hennig documents how ideas of nation and the myths of "nature" inevitably associated with them produce very different cultural assumptions, which in turn shape specifically "national" environmental practices and laws. Hennig notes that comparisons between local and global views often ignore older impacts of national discourses, "die sich auf das Verhältnis von Natur und Kultur beziehen und die zugleich in einem engen Zusammenhang mit Auffassungen von Nation und nationaler Identität stehen" (2). He concludes that the troubled concept of nature obstinately retains older prejudices with national overtones and that, regardless of how "nationale Identität konstruiert wird," it directly impacts "die Diskussion von Umweltfragen" (377). The very question of what qualifies as a relevant environmental problem (not to mention, solution), is frequently dictated by long-held ideas about national heritage: "Was aber als 'Umweltproblem' betrachtet wird, was als dessen Ursache ausgemacht wird und was zur Lösung der 'ökologischen Krise' der Gegenwart vorgeschlagen wird, hängt offenbar in noch weitaus stärkerem Maße als bislang bekannt vom jeweiligen nationalen Kontext ab" (377).

In sum, as the environmental humanities seek to address the global problems of the Anthropocene, they must also continue to acknowledge their (not always critical) engagement with national, linguistic, or global delineations, just as environmentalists broadly must engage with national laws that shape our local and regional experiences but also impact the larger, planetary, systems. There is no simple solution to the problem of scale in the Anthropocene.

HEATHER I. SULLIVAN

Trinity University

The Nation-State Model and German Studies: An Applied Linguistics Perspective My response to the question "Does German Cultural Studies need the NationState Model?" is modulated by three identities: (1) I am a Germanist with a specialization in applied linguistics and second language studies. In the first part of my response, I will show that my subfield has no ideological and methodological 
links to the nationalistic tendencies of nineteenth-century German linguistics and philology. (2) I am also a former language program director, which provides a perspective that complicates the relation between applied linguistics research and the nation-state model to the German Studies curriculum. Therefore, in the second part, I will describe how findings in my field guide (and fail to guide) the selection of cultural content in the undergraduate curriculum. (3) Currently, I am an administrator who supports academic affairs across eleven language programs, a role that informs an institutional perspective on the nation-state model. In the final part of my response, I will argue that although the nation-state model is imperfect, German departments need to carefully consider local particularities as they evaluate alternative institutional frameworks for German Studies.

1. The Field of Applied Linguistics. Established as a modern research area only in the second half of the twentieth century, most of the early contributions in SLA research were made by scholars affiliated to public research institutions in the United States. This work happened in direct response to geostrategic challenges of the Cold War era. Fueled by federal funding, researchers were charged with identifying adequate mechanisms to select high-aptitude learners and to teach foreign languages effectively. Psychology provided a widely-accepted learning theory, behaviorism, as well as a set of standardized psychometric methods. Some of the findings generated at the dawn of this young research field sanitized the German language classroom by removing the traditional canon-oriented grammartranslation method and replacing it with the sterile audio-lingual approach.

When researchers discovered that the audio-lingual methods failed to generate the postulated proficiency gains in many learners, and after cognitive scientists debunked the underlying behavioristic theory, new paradigms emerged in the late 1970s in the form of communicative language teaching and content-based language instruction. These curricular frameworks provided opportunities to bring authentic materials into the language classroom. Since the early 1990s, literacy-centered approaches to collegiate language instruction - spearheaded by Germanists at Stanford University (Elizabeth Bernhardt), the University of Texas at Austin (Janet Swaffar, Katherine Arens), Georgetown University (Heidi Byrnes), and the University of California at Berkeley (Claire Kramsch)—went further and mandated the integration of cultural content and language at all levels of the undergraduate curriculum. Curricular principles developed by this cluster of Germanists inspired colleagues in other languages and were subsequently endorsed by the major professional organizations, including the Modern Language Association. The impact of this scholarship on the content of undergraduate German courses can hardly be overestimated.

2. The Undergraduate Curriculum. The recognition that content represents the central mechanism of the second language acquisition process created a challenge. Cultural content in the undergraduate classroom is more than a language learning vehicle. It exposes each new generation of German students to a set of schemata that prompt them to construct a preliminary understanding of what it means to study German in college. 
At the lower-level of the undergraduate curriculum, it is unclear to what degree cultural content originates from a transnational or nation-state curricular model. On the one hand, the vast majority of conference and journal contributions on curricular matters promote a progressive view of cultural content that challenges the nation-state model. Today's thought-leaders on culture-centered, contentbased language teaching suggest that undergraduate students should be consistently exposed to artifacts and discourses from a broad variety of Germanophone cultures and subcultures. Such selections not only intend to help students at very early stages to develop sociolinguistic competences, but they also help fostering an understanding that a broad range of German varieties are used in a multitude of speech communities within and outside Central Europe, and that not everybody in Central Europe uses the German language as a medium of communication. Beginning German students are exposed to learning experiences that destabilize nationalistic simplifications linking language with ethnicity and territory. On the other hand, this progressive understanding of cultural content is rarely reflected in cultural representations in German language textbooks. Those of our undergraduate students who receive most of their cultural information from their instructional materials are exposed to a uniform set of representations: With exceptions of tokenized representations, characters in commercial textbooks are biodeutsch-Germans with a non-immigrant background-, the territorial focus is Central Europe, and the everyday culture depicted is that of a privileged Bildungsbürgertum preoccupied with Karneval, Kaffeeklatsch, and Kürbiskernbrot.

3. Institutional Structures. The traditional institutional structure in our field is the German Department. This construct suggests that despite methodological and theoretical variations and a wide range of discourses, genres, periods, and concerns, we form a scholarly community based on our shared concern for the German language and the analysis of cultural and societal products, practices, and perspectives rendered in the German language or generated in Germanspeaking communities.

The national language / literature / culture department fails to build a robust scholarly community. Students and colleagues are voting with their feet. Instead of exchanging ideas with their departmental colleagues, faculty members gravitate towards centers where they find intellectual homes through more rewarding interactions among non-Germanists. Graduate students drop out, if required course work or canonical reading lists have little or no relevance for their dissertation projects and their aspirations as university teachers that go beyond German language and literature classes. Many undergraduates with advanced-level German language proficiency and an interest in Germanophone societies are not attracted to a literature and cultural studies major and are instead drawn to transnational programs such as European Studies and International Studies. For undergraduates interested in teaching German at the K-12 level, a degree in Foreign Language Education that fulfills teacher certification requirements is often a more intelligent career choice than a degree with a specialization in German literature and culture. 
If the nation-state template for institutional structures creates an unattractive academic home for many colleagues and a curriculum that does not resonate with our students' needs and wants, one could hastily conclude that maintaining the institutional status quo of national language / literature / culture departments bears more risks to the future of the field than reforming our administrative structures. But is it the department structures that are responsible for the systemic failures of our curricula? Probably not. There are opportunities to update curricula "from the inside," and some departments have made progress in implementing transnational approaches to research and teaching despite maintaining the institutional structure. These changes manifest themselves in a (slightly) more diverse junior professoriate with (significantly) more diverse intellectual interests compared to any past generation of Germanists in North America. A new professional organization, the Diversity, Decolonialization, and the German Curriculum network, articulates many of the concerns voiced by today's most engaged and engaging students and faculty members. This platform offers colleagues opportunities to challenge the nation-state model in their scholarship and to become changemakers in the field through their focus on curriculum.

The nation-state model as a template for institutional structures is arbitrary. Therefore, we have options: For example, departments with stable enrollment trends can largely maintain the status quo while acknowledging and confronting the nationalistic legacy of our fields from within and optimizing the individualizing curricular pathways for their students. Alternatively, struggling programs can be proactive and forge partnerships. The primary goal should not be a focus on operational efficiencies, but to create stronger units that truly benefit the faculty and the needs and wants of local student bodies. Becoming a part of a larger unit-if it does not happen just for economic reasons and/or as a result of an administrative top-down dictate-may be a positive development. The leadership of a single, large, and stable unit is more likely to gain a "seat at the table" and act as a robust advocate for languages and partner in campus-wide strategic planning efforts compared to the thinning voices of multiple chairs representing small, shrinking departments with miniscule enrollment.

My particular vantage point allows only one direct response to the question that inspired this forum: No, German Cultural Studies does not need the nation-state model. A transnational orientation of the field has more potential to result in attractive curricula and resonates more strongly with teaching philosophies and research activities of the majority of the current and future professoriate. However, this does not mean that the German department needs to be abolished. Various structural options allow a broad spectrum of scholarship and teaching. Instead of identifying one particular model and claiming that it would optimally serve our field at all kinds of institutions, I want to emphasize that decisions that relate to departmental structures must be calibrated to local particularities, including size of program and institution, enrollment trends, shifts in local student demographics, faculty interest and strengths, availability of robust partners, and 
the level of overall enthusiasm (or lack thereof) for language education among the campus's senior leadership. Mindfulness of local conditions is far more relevant to successful program transformations than recommendation of authorities in the field.

There is a lot of uncertainty regarding the future of our field; however, one fact remains clear: German Studies at American universities will only prosper if we manage to develop curricula that reattract undergraduate students to our major and if we offer programs at the graduate level that resonate with the the complex demands of both the academic and alt-ac job markets. Clinging to the nationstate model for curriculum will make this task far more difficult. Whether curricular transformations can be realized within the structures of a German Department or larger units are more effective to generate the necessary changes, depends on local particularities.

PER URLAUB

Middlebury College

\section{German's Anti-National Niches}

I have come to understand the "field" of German as a patchwork of niches, with each niche tending to imagine itself as the field. But there are constant reminders that this is not the case, especially in the job market but also in a "big tent" phenomenon like the GSA. One can view this negatively as a lack of disciplinary unity of purpose, or positively as a kind of diversity and methodological pluralism that many fields lack. This basic structure and its historical permutations are described extensively in German Studies in the United States (Hohendahl).

This disciplinary constellation is important to keep in mind when assessing the role of nation and nationality in the constitution of the field. Germanics, or its particular niche I entered in the 1990s, at the time could not have been more anti-national in its self-conception. My B.A. was in comparative literature, and the decision between a $\mathrm{PhD}$ in German vs. comp lit in those days among graduate cohorts of my acquaintance was largely a pragmatic one. Back then, comp lit was the acknowledged intellectual center, but "at least in German you will have a clear specialization." German was, according to this model, "comparative literature from the vantage point of the German language." “German” was the Sprachraum within which literary and comparative topics were pursued, without specifically privileging German literature or culture as such. This model was partly sustained internationally, ironically through the emulation of the German system. For example, my U.S. PhD. was in German, but the academic units I was associated with in Germany were interdisciplinary research groups or institutes for allgemeine und vergleichende Literaturwissenschaft. 
In line with the main thrust of Jakob Norberg's recent essay, one can certainly wonder whether this model is sustainable - or how viable it ever was. But this question should be answered, I would argue, based on the "patchwork of niches" model, which supposes that the reality of our field, for better or worse, is that people enter it for vastly different reasons and receive very different kinds of training along the way. In its structure, I would argue, German is (and sometimes strives to be) more like U.S. English departments, with the crucial difference of scale. The kind of disciplinary range that can be supported in an English department or in the humanities at German-language universities cannot be easily and autonomously housed by U.S. Germanics. This has the effect that German's "niches" can easily become an intellectual backwater in relation to other disciplines. German's subfields risk dwindling their autonomy and/or becoming derivative through borrowing and importing from larger disciplines and from Germany. This particular constellation leads German as a field to be structured in a way that is different than other U.S. language-literature departments (e.g., French, Spanish, Italian), which still tend to cleave more closely to the study of national literatures. Even English departments for all of their range give the impression that the detailed study of the literary canon (from Chaucer to Virgina Woolf and beyond) remains the norm and precondition. In German departments most everyone knows all of the novels of Kafka-and it is expected-but much fewer know all of Goethe's. This situation is partly a result of a German-language-based comparative approach and of the anti-national affect that often accompanies it. If it is true that the Anglophone world is woefully ignorant about German literature, as my colleague Jeffrey Sammons has suggested (59), then what are we to make of a field of German that perpetuates the same blind spots?

My own trajectory did not entirely allow me to continue to work within the model of "comparative literature in German." Though I benefitted from the persistent exposure to eclectic mixes of periods, genres, disciplines, and methods, and my publications also reflect this, the reality of my role, coming to Yale's German department as junior faculty in the 2000s, was that I had to retrain myself on the job for the national language-literature side of the discipline. As far as I know, Yale at that time had (and has) the reputation of being one of the most comparatist of all German departments, but it was still (and remains) bound by traditional national-philological expectations, which come from the expectations of students, administrators, the field, and, perhaps more subtly, by the models set by other language-literature departments at this institution. Thus, without entirely realizing it, I adapted in the direction of "German" and Germanistik, and, at the same time, I began to set aside the professional goals and mimetic rivalries that radiated from neighboring fields like comp lit (and also philosophy). Many aspects of such developments are debatable and questionable, but they seem to be worth mentioning in the context of Jakob Norberg's essay, which poses serious questions about the directions German as a field should consciously move in. 
But the field is ultimately a collection of individual cases. My point is that as much as we try to consciously "set agendas," which is a core function of our intellectual autonomy, we are also very much a product of what the people and institutions around us expect us to be. This means in the case of German, for example, that these days range and flexibility (which come in many different forms) are typically more prized than excellence in a particular specialization (which is often perceived as "narrowness"). A colleague from another institution once put it: "Most German departments are looking for utility players."

In 2003, Sammons argued that U.S. German studies always defined itself through its reactions to the outside environment-in other disciplines and in the society at large. In the past decades, U.S. Germanists' changing relation to "German-ness" (however it is conceived) is surely an example of this. The intensely anti/post-national, comparatist (anti-Germanistik) field (or niche) that I entered in the 1990s corresponds to the post-89 situation of Germany itself. This Germany was not only reunified, but in its reunification it sought to overcome its own nationhood and embody the commitment to a European identity. But now, post-2016, with the E.U. embattled on many fronts and struggling to contain nationalist-populist upsurges, it is apparent that the post-national attitude was partly aspirational. Perhaps it should remain as an aspiration, but Germany at the moment is barely maintaining its position as model European citizen and economic anchor. This is the context in which U.S. German departments feel the pressure to acknowledge their dependency on the ups and downs of German nationhood without falling back into overt nationalism (except perhaps in the kind of strategic retreat suggested by Norberg).

Given the contemporary politics of Europe and the U.S., one could argue that a new explicitly "anti-national Germanics" is now more important than ever. But it is not entirely clear to me how this should look. I am reminded, for example of the alarm sounded by Leif Weatherby at the last meeting of the Goethe Society of North America. While big tent Germanics (including philosophy and theory) reflexively continues its post-war anti-fascist projects of rescuing the canon of German letters from nationalist appropriation, new waves of nationalism and alt-right trolls are again looking to German-language authors to support their worldviews.

Norberg's claim that "German literary studies was the nationalist discipline par excellence" (13) contains more than a grain of truth, but in order to figure out where this leaves us, it is worth considering some counterarguments. For example, there are comparatists who argue, often taking their cues from the Schlegels and Nietzsche, that philology is a critical and methodological project without an essential relation to nationality (Benne, Gumbrecht, Hamacher, Pollock, Szondi, HellerRoazen). But none of these scholars would disagree with Norberg that philology has also played a leading role in consolidating national (and nationalist) traditions.

It is also noteworthy that, as Norberg argues, the modern origin of the nationalist paradigm for literary study, Herder, is equally the originator of the modern idea of Weltliteratur. This Herderian provenance was inherited by Goethe, who put the term Weltliteratur into circulation, where it was notably picked up by Marx and En- 
gels in the 1848 Manifest der kommunistischen Partei. Though this notion was arguably never able to overcome its nationalistic and monolingual flipside (see Mani), it is a reminder of the fact that German literature, by virtue of its belatedness, was always Weltliteratur in ways that French, English, and Spanish literatures were not. The canon of European and world literature as we know them were partly a creation of the German classical-romantic period. This narrative is itself open to a nationalist interpretation, insofar as it seems to give Germany credit for Europe; but one could also say, without invoking a full-blown Sonderweg, that the case of German-language literature is more similar to Russian (which also explains the tight symbiosis of these two traditions well into the twentieth century). One could also argue that to study German (literature) in the U.S. is already an instance of Weltliteratur.

Norberg also suggests that for German departments and Germanists the corpus of "theory" inevitably leads back to the national paradigms of canonization. This is certainly partly true - but what shall we do about the case of "French theory"? which, on the one hand, follows the paradigm of national attribution, but which, on the other hand, is also an example of theory-diaspora and internationalization. Here one can think of Barbara Cassin's Dictionary of Untranslatables, but perhaps the larger point is that the French theory wave was itself already a second wave in relation to older traditions of German philosophy and theory. The comparable problem of the national vs. the international in the earlier historical moment is captured in categorizations such as "German Romanticism" or "German Idealism." But why is there no comparably influential term for distinguishing the traditions of "German (or Austrian?) psychology" or "German sociology"? If theory, like literature, exists in a comparative and historical space, is it legitimate to view this space through the lens of a specific Sprachraum? But is there any other access to these traditions except through Spracbräume (with English as the current default option)?

If, as I have suggested, the history of Germanics in the U.S. is a story of adaptability in relation to external pressures, this can be viewed as a success story or as problematic with respect to expectations of continuity necessary to coherently define a discipline as a discipline. Either way, the relation to theory (versus or in addition to literature) would be central to this development. At present, within the niche of my own institution, the interdisciplinary role of German lies increasingly in our ability to curate and supply linguistic and historical competency for projects related to the nineteenth-century infrastructure of the main disciplines of the humanities and social sciences. The importance of this work varies depending on the discipline (and on whom you ask), but there is no denying that German contains large chunks of the historical archive of central but in many cases predominantly (and increasingly) Anglophone fields, such as Philosophy, Sociology, Psychology, History, Music, History of Art, Classics, as well as Religious Studies, Near Eastern Studies, Judaic Studies, Media Theory-in addition to the twentieth-century interdisciplinary extensions collected under the general heading of "theory."

Given this framework, the place of German literature remains a serious question. It risks becoming relegated to the old nationalist project in the context of which it 
was often written and canonized (following, for example, the central thesis of Pascale Casanova's World Republic of Letters). And yet literature cannot be entirely set aside. First, very pragmatically, because there is an expectation that German departments teach German literature in order to retain parity with other US language-literature programs. When and if our larger peers start to fall or transform, so will we-but there is no advantage in going it alone. Second, the "roots of other disciplines" model does not allow so many large fields and complex genealogies, conceived historically, to comfortably fit within the very small discipline of U.S. Germanics. Finally, Norberg's objection remains: to focus on the "German roots" is not comparative enough, especially if it is being pursued by a German department.

It is difficult for German to avoid some kind ancillary position. For example, to focus primarily on contemporary language and culture alone, though a key support structure and (for now) a source of many potential enrollments, does not appear to offer a broad enough disciplinary or interdisciplinary mandate for an academic department of a research university. And the rigorous institutionalization of this version of contemporary German Studies would again rely on historical and methodological roots that either lie in other disciplines and/or would need to account for the historical depth and context provided by the traditions of historical-critical hermeneutics, the legacy and limitations of which is not easily separable from literary studies.

There are no easy solutions, especially given the role of external factors, not least "the market," the economy, and the situation of the globe- but also the range of methods, trainings, motivations, which comprise the field of German as currently constituted. Given this situation, I would say that the main question at the moment is how much pluralism and national-orientation we can live with and where we, individually and collectively, feel that we need to draw the line. At the undergraduate level, this may mean uncomfortable compromises between the national(ist) enthusiasms of certain students vs. the kind of critical reflections that Norberg calls for. At the graduate level, it may mean renewed questioning of the main agendas of our various niches, especially with respect to training and research goals. What made sense thirty years ago and may have even been very successful (e.g., the U.S. field's confrontation of the legacies of Nazism), might require rethinking in light of the contemporary landscape within and beyond academia. KIRK WETTERS Yale University

\section{Works Cited}

Adelson, Leslie. The Turkish Turn in Contemporary German Literature: Towards a New Critical Grammar of Migration. Palgrave Macmillan, 2005.

Ahmed, Sara. Queer Phenomenology: Orientations, Objects, Others. Duke UP, 2006. 
Anderson, Elijah. “The White Space.” Sociology of Race and Ethnicity, vol. 1, no. 1, 2015, pp. 10-21.

Anderson, Mark M. "German Intellectuals, Jewish Victims: A Politically Correct Solidarity." Chronicle of Higher Education, 19 October 2001, B1-10.

Arendt, Hannah. "What is Authority?" The Portable Hannah Arendt, edited by Peter Baehr, Penguin, 2000, pp. 462-507.

Aydemir, Fatma, and Hengameh Yaghoobifarah (eds.). Eure Heimat ist unser Albtraum. Ullstein fünf, 2019.

Beard, Laura; Claudia Kost; Victoria Ruetalo; Carrie Smith, and Micah True. "From Silos to Networks: Re-envisioning Undergraduate and Graduate Programs in a Modern Languages Department." ADE $\mathcal{E}^{\circ}$ ADFL Bulletin: Globalization and Literary Studies, vol. 45, no. 1, 2019, pp. 109-21.

Benseler, David P.; Craig W. Nickisch, and Cora Lee Nollendorfs (eds.). Teaching German in Twentieth-Century America. U of Wisconsin P, 2001.

Berg, Maggie, and Barbara K. Seeber. The Slow Professor: Challenging the Culture of Speed in the Academy. U Toronto P, 2016.

Bernhardt, Elizabeth. Reading Development in a Second Language: Theoretical, Empirical, and Classroom Perspectives. Ablex, 1991.

Bernhardt, Elizabeth B., and Russell A. Berman. "From German 1 to German Studies 001: A Chronicle of Curricular Reform." Die Unterrichtspraxis / Teaching German, vol. 32, no. 1,2000 , pp. 22-31.

Bérubé, Michael, and Jennifer Ruth. The Humanities, Higher Education, and Academic Freedom. Palgrave Macmillan, 2015.

Bithell, Jethro (ed.). Germany — A Companion to German Studies. Methuen and Co.Ltd, 1932.

Byrnes, Heidi, and Susanne Kord. "Developing Literacy and Literary Competence: Challenges for Foreign Language Departments." SLA and the Literature Classroom: Fostering Dialogues, edited by Virginia Scott and Holly Tucker, Heinle, 2002, pp. 35-74.

Casanova, Pascale. The World Republic of Letters. Translated by M. B. Debevoise, Harvard UP, 2004.

Ceuppens, Jan, Françoise Gallez, and Torsten Leuschner. "Germanistik/Deutsch im belgischen Hochschulwesen. Flandern und Frankophonie im Vergleich.” Zukunftsfragen der Germanistik. Beiträge der Germanisten-Tagung 2011 mit den Partnerländern Belgien, Frankreich, Niederlande, Luxemburg, Wallstein, 2012, pp. 60-76.

Charbonneau, Léo. “The Rise of the Monoglots” University Affairs, 5 August 2008, www.universityaffairs.ca/features/feature-article/the-rise-of-the-monoglots/.

Comaroff, Jean, and John L. Comaroff. Theory from the South: Or, how Euro-America is evolving toward Africa. Paradigm 2012.

Conrad, Sebastian. What is Global History? Princeton UP, 2016.

Cornell, Drucilla. Law and Revolution in South Africa: Ubuntu, Dignity, and the Struggle for Constitutional Transformation. Fordham UP, 2014.

Cornish, Matt. "Migration: Common and Uncommon Grounds at Berlin's Gorki Theater." Postdramatic Theater and Form, edited by Michael Shane Boyle, Matt Cornish, and Brandon Woolf, Methuen Drama, 2019, pp. 179-95.

Costabile-Heming, Carol Anne, and Rachel J. Halverson (eds.). Taking Stock of German Studies in the United States: The New Millenium. Camden House, 2015.

Deleuze, Gilles, and Felix Guattari. Kafka: Toward a Minor Literature. U of Minnesota P, 1986.

—.Anti-Oedipus: Capitalism and Schizophrenia. Continuum, 2003. 
Demoor, Marysa (ed.). De kracht van het woord. 100 jaar Germaanse filologie aan de RUG (1890-1990). Studia Germanica Gandensia, 1991.

Denham, Scott; Irene Kacandes, and Jonathan Petropoulos (eds.). A User's Guide to German Cultural Studies. U. of Michigan P, 1997.

Derrida,Jacques. Monolingualism of the Other; or, the Prosthesis of Origin. Stanford UP, 1999.

De Smedt, Marcel. Honderd jaar Germaanse filologie in Leurven (1894-1994). Germanistenvereniging Leuven, 1994.

Dürbeck, Gabriele. "Narrative des Anthropozän - Systematisierung eines interdisziplinären Diskurses." Kulturwissenschaftliche Zeitschrift, vol. 3, no.1, pp. 1-20.

Eaton Group, The. "A Multilingual Turn in German Studies: Premises, Provisos, and Prospects.” Die Unterrichtspraxis / Teaching German, vol. 52, no. 1, 2019, pp. 14-31.

E1-Tayeb, Fatima. Die Konstruktion des Anderen in der postmigrantischen Gesellschaft. Transcript 2016.

Fischer, Joachim, and Manfred Schewe. "Deutschunterricht und Germanistikstudium in der Republik Irland.” Deutsch als Fremdsprache - Ein internationales Handbuch, vol. 2.1, edited by Gerhard Helbig et al., De Gruyter, 2001, pp. 1471-80.

Florén, Anna, and Emelie Höglund (eds.). Norden återupptäcker Tyskland. Nya perspektiv på gamla relationer, Skyline, 2013.

Foucault, Michel. Discipline and Punish: The Birth of the Prison. Translated by Alan Sheridan, Random House, 1977.

Frevert, Ute. "Europeanizing Germany's Twentieth Century," History and Memory, vol. 17, no. 1-2, 2005, pp. 87-116

Fuchs, Anne, and Mary Cosgrove. "Introduction: Germany's Memory Contests and the Management of the Past." German Memory Contests: The Quest for Identity in Literature, Film, and Discourse since 1990, edited by Anne Fuchs, Mary Cosgrove, and Georg Grote, Boydell \& Brewer, 2006, pp. 1-22.

Germanistik as German Studies: Interdisciplinary Theories and Methods. Special issue of The German Quarterly, edited by Paul Michael Lützeler and Jefrey Peck, vol. 62, no. 2, Spring 1989.

Gilman, Sander L. "Why and How I Study the German." The German Quarterly, vol. 62, no. 2, Spring 1989, pp. 192-204.

Gramling, David. "The New Cosmopolitan Monolingualism: On Linguistic Citizenship in Twenty-First Century Germany." Unterrichtspraxis/Teaching German, vol. 42, no. 2, 2009, pp.130-40.

Haakenson, Thomas O.; Tirza True Latimer; Carol Hager, and Deborah Barton (eds.). Becoming TransGerman: Cultural Identity beyond Geography. Peter Lang, 2019.

Habermas, Jürgen. Zur Verfassung Europas. Ein Essay. Suhrkamp, 2011.

Haines, Brigid. "The Eastern Turn in Contemporary German, Swiss and Austrian Literature." Debatte: Journal of Contemporary Central and Eastern Europe, vol. 16, no. 2, 2008, pp. $135-49$.

Heidegger, Martin. Unterwegs zur Sprache. Gesamtausgabe, vol. 12, Vittorio Klostermann, 1985.

Heise, Ursula. Sense of Place and Sense of Planet: The Environmental Imagination of the Global. Oxford UP, 2008.

Hennig, Reinhard, Umwelt-engagierte Literatur aus Island und Norwegen. Ein interdisziplinärer Beitrag zu den environmental humanities. Peter Lang, 2014.

Herder, Johann Gottfried. Briefe zu Beförderung der Humanität. Werke, vol. 7, edited by Hans Dietrich Irmscher, Deutscher Klassiker Verlag, 1991.

Hohendahl, Peter U. Building a National Literature: The Case of Germany, 1830-1870. Translated by Renate Baron Franciscono, Cornell UP, 1989. 
-. (ed.). German Studies in the United States: A Historical Handbook. MLA, 2003.

Höhne, Steffen, and Manfred Weinberg (eds.). Franz Kafka im interkulturellen Kontext. Böhlau, 2019.

Holub, Robert C. [Contribution to Forum "Is Literature still central to German Studies?", edited by Frank Trommler]. The German Quarterly, vol. 80, no. 1, 2008, pp. 101-02.

hooks, bell. "Talking Race and Racism." Teaching Community: A Pedagogy of Hope, Routledge, 2003, pp. 25-40.

Isenberg, Noah. "Developments in German Jewish Studies from 1980 to the Present." German Studies in the United States: A Historical Handbook, edited by Peter U. Hohendahl, MLA, 2003, pp. 299-307.

Kagel, Martin, and William Collins Donahue. "An Immodest Proposal: Reenvisioning German Studies through European Integration.” Costabile-Heming and Halverson, Taking Stock of German Studies in the United States: The New Millenium, pp. 272-89.

Kontje, Todd. Imperial Fictions: German Literature Before and Beyond the Nation-State. U of Michigan P, 2018.

Kramnick, Jonathan, and Anahid Nersessian. "Form and Explanation." Critical Inquiry, vol. 43, 2017, pp. 650-69.

Kramsch, Claire. Context and Culture in Language Teaching. Oxford UP, 1993.

Langer, Roy. Die Darstellung Deutschlands in den dänischen Medien. Deutscher Universitätsverlag, 2003.

Languages connect-Ireland's Foreign Languages Strategy in Education 2017-2026, Department of Education and Skills, Dublin 2017, www.education.ie/en/Schools-Colleges/ Information/Curriculum-and-Syllabus/Foreign-Languages-Strategy/fls_languages_ connect_strategy.pdf.

Layne, Pricilla. "On Racism without Race: The Need to Diversify Germanistik and the German Academy." Who can speak and who is heard/hurt? Facing Problems of Race, Racism, and Ethnic Diversity in the Humanities in Germany, edited by Mahmoud Arghavan, Nicole Hirschfelder, Luvena Kopp, and Katharina Motyl, transcript, 2019, pp. 217-38.

Lennox, Sarah. "German Studies and Globalization: Beyond Eurocentrism.” The German Quarterly, vol. 78, no. 4, 2005, pp. 517-20.

Leuschner, Torsten, and Achim Küpper. "Die Germanistik im mehrsprachigen Bildungssystem Belgiens.” Mitteilungen des Deutschen Germanistenverbandes vol. 64, no. 1, 2017, pp. 51-56.

Levine, Caroline. Forms: Whole, Rhythm, Hierarchy, Network. Princeton UP, 2015.

Lionnet, Françoise, and Shu-mei Shih. Minor Transnationalism. Duke UP, 2005.

Lochtman, Katja, and Barbara Obst. "Germanistik in Belgien / Brüssel." Convivium, vol. 5, 2012, pp. 81-90.

Loentz, Elizabeth (ed.). "Forum: Feminism in German Studies.” The German Quarterly, vol. 91, no. 2, 2018, pp. 202-27.

Lohnes, Walter F.W., and Valters Nollendorfs (eds.). German Studies in the United States: Assessment and Outlook. U of Wisconsin P, 1976.

Long, John. "German Studies and Minority Communities." The German Quarterly, vol. 73, no. 1,2000, pp. 19-20.

Looney, Dennis, and Natalia Lusin. Enrollments in Languages other than English in United States Institutions of Higher Education, Summer 2016 and Fall 2016: Final Report. MLA, 2019.

Lützeler, Paul Michael, and Peter Höyng (eds.). Transatlantic German Studies: Testimonies to the Profession. Camden House, 2018. 
Mani, B. Venkat. Recoding World Literature: Libraries, Print Culture, and Germany's Pact with Books. Fordham UP, 2017

McCarthy, John A. "The History of the Organization of German Departments in the United States." German Studies in the United States: A Historical Handbook, edited by Peter Uwe Hohendahl, MLA, 2003, pp. 27-54.

McCarthy, John A., and Katrin Schneider (eds.). The Future of Germanistik in the USAChanging our Prospects, Vanderbilt UP, 1996.

Mommsen, Hans. "History and National Identity: The Case of Germany." German Studies Review, vol. 6, no. 3, 1983, pp. 559-82.

Mora, Terézia; Imran Ayata; Wladimir Kaminer, and Navid Kermani. "Ich bin ein Teil der deutschen Literatur, so deutsch wie Kafka”[Interview]. Literaturen, vol. 4, 2005, pp. 26-31.

Morris, Leslie. "How Jewish is German Studies? How German is Jewish Studies?" The German Quarterly, special issue on German-Jewish and Jewish-German Studies, vol. 82, no. 3, Summer 2009, pp. vii-xii.

Nietzsche, Friedrich. Human, all too Human II and Unpublished Fragments. Translated by Gary Handwerk, Stanford UP, 2013.

-. Human, all too Human: A Book for Free Spirits. Translated by R.J. Hollingdale, Cambridge UP, 2004.

-.Menschliches, Allzumenschliches. Kritische Studienausgabe, vol. 2, edited by Giorgio Colli and Mazzino Montinari, DTV / de Gruyter, 1999.

-. Kommentar zu Band 1-13. Kritische Studienausgabe, vol. 14, edited by Giorgio Colli and Mazzino Montinari, DTV / de Gruyter, 1999.

Norberg, Jakob. “German Literary Studies and the Nation.” The German Quarterly, vol. 91, no.1, 2018, pp. 1-17.

"Open Letter to the AATG: A Ten-Point Program of the Diversity, Decolonization, and the German Curriculum (DDGC) Collective," docs.google.com/forms/d/e/ 1FAIpQLSe1rmao3_aAcB5wy2NfnG1vvD5KMKajPIgq41y8dRfgheCurQviewform.

Parry, Christoph. "Europas transkulturelle Literaturen. Das Ende der Nationalliteratur?" Migration in Deutschland und Europa im Spiegel der Literatur. Interkulturalität-Multikulturalität - Transkulturalität, edited by Hans W. Giessen and Christian Rink, Frank \& Timme, 2017, pp. 111-25.

Peters, George F. “Editor's Corner.” Unterrichtspraxis / Teaching German, special issue on Promoting Diversity in German, vol. 25, no. 2, 1992, pp. vii-viii.

Pratt, Mary Louise. "Building a New Public Idea about Language." Profession, 2003, pp. 110-19.

Renan, Ernest. "What is a Nation?" Nation $\Xi$ Narration, edited by Homi Bhabha, translated by Martin Thom, Routledge, 2013, pp. 8-22.

Sammons, Jeffrey. "The Constituencies of Academics and the Priorities of Germanists." German Studies in the United States: A Historical Handbook, edited by Peter Uwe Hohendahl, MLA, 2003, pp. 55-64.

Schaumann, Caroline, and Heather I. Sullivan (eds.). German Ecocriticism in the Anthropocene. Palgrave Macmillan, 2017.

Schmidt, Hans-Jürgen (ed.). Die Expressionismusdebatte. Materialien zu einer marxistischen Realismuskonzeption. Suhrkamp, 1973.

Schneider, Peter. "If the Wall came tumbling down." The New York Times Magazine, 25 June 1989, pp. 22-70.

Schramm, Moritz. "Probleme und Perspektiven. Zur Stellung der deutschsprachigen Literatur im dänischen Universitätsbetrieb.” Literaturvermittlung. Texte, Konzepte, Praxen 
in Deutsch als Fremdsprache und den Fachdidaktiken Deutsch, Englisch, Französisch, edited by Simone Schiedermair, Iudicium, 2017, pp. 161-83.

Searle, John R. The Construction of Social Reality. The Free Press, 1995.

Seeba, Hinrich. "Critique of Identity Formation: Toward an Intercultural Model of German Studies." The German Quarterly, vol. 62, no. 2, Spring 1989, pp. 144-54.

Smith, Neil. Uneven Development: Nature, Capital, and the Production of Space. U of Georgia $\mathrm{P}, 2008$.

Spector, Scott. Prague Territories: National Conflict and Cultural Innovation in Franz Kafka's Fin de Siècle. U of California P, 2000.

-.Modernism without Jews? German-Jewish Subjects and Histories. U of Indiana P, 2017.

Streeck, Wolfgang. How will Capitalism end? Verso, 2016.

Suchoff, David. Kafka's Jerwish Languages: The Hidden Openness of Tradition. U of Pennsylvania P, 2012.

Swaffar, Janet, and Katherine Arens. Remapping the Foreign Language Curriculum: An Approach Through Multiple Literacies. MLA, 2005.

Swaffar, Janet; Katherine Arens, and Heidi Byrnes. Reading for Meaning: An Integrated Approach to Language Learning. Prentice-Hall, 1991.

Tatlock, Lynne. "Response to Hohendahl." The Future of Germanistik in the USA-Changing our Prospects, edited by John McCarthy and Katrin Schneider, Vanderbilt UP, 1996, pp. 29-34.

Terreblanche, Sampie. Lost in Transformation: South Africa's Search for a New Future since 1986. KMM, 2012.

Tooze, Adam. Crashed: How a Decade of Financial Crises changed the World. Viking, 2018.

Trommler, Frank (ed.). Germanistik in den USA. Neue Entwicklungen und Methoden. Westdeutscher Verlag, 1989.

Trump, Donald. "Remarks by President Trump to the 72nd Session of the United Nations General Assembly.” 19 September 2017, www.whitehouse.gov/briefings-statements/ remarks-president-trump-72nd-session-united-nations-general-assembly/.

Tuck, Eve, and K. Wayne Yang. "Decolonization is not a Metaphor." Decolonization: Indigeneity, Education E' Society, vol. 1, no. 1, 2012, pp.1-40.

Watchman, Renae; Carrie Smith, and Markus Stock (eds.). Building Transdisciplinary Relationships: Indigenous and German Studies, special issue of Seminar: A Journal of Germanic Studies, 2019, vol. 54, no. 4.

Weatherby, Leif. "Irony and Redundancy: The Alt Right, Media Manipulation, and German Idealism.” b2o, 24 June 2019, www.boundary2 .org/2019/06/leif-weatherby-irony-andredundancy-the-alt-right-media-manipulation-and-german-idealism/.

Wucherpfennig, Wolf. Vom Kloster zur Wissensfabrik. Erinnerungen und Reflexionen. Königshausen \& Neumann, 2007.

Yildiz, Yasemin. Beyond the Mother Tongue: The Postmonolingual Condition. Fordham UP, 2012.

Zalasiewicz, Jan, et al. "Results of Binding Vote by AWG, released 21rst May 2019.” Subcommission on Quaternary Stratigraphy: Working Group on the 'Anthropocene,' quaternary. stratigraphy.org/working-groups/Anthropocene/. 